\title{
Randomized controlled non-inferiority trial investigating the effect of 2 selective dry-cow therapy protocols on antibiotic use at dry-off and dry period intramammary infection dynamics
}

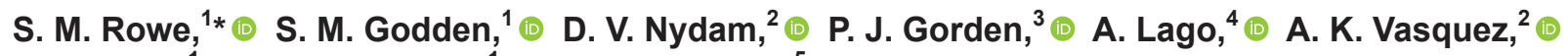 \\ E. Royster, ${ }^{1}$ () J. Timmerman, ${ }^{1}$ and M. J. Thomas ${ }^{5}$ () \\ ${ }^{1}$ Department of Veterinary Population Medicine, University of Minnesota, St. Paul 55108 \\ ${ }^{2}$ Department of Population Medicine and Diagnostic Sciences, College of Veterinary Medicine, Cornell University, Ithaca, NY 14853 \\ ${ }^{3}$ Veterinary Diagnostic and Production Animal Medicine, lowa State University, Ames 50011 \\ ${ }^{4}$ Research and Development Department, DairyExperts, Tulare, CA 93274 \\ ${ }^{5}$ Dairy Health and Management Services, Lowville, NY 13367
}

\section{ABSTRACT}

Selective dry-cow therapy (SDCT) could be used to reduce antibiotic use on commercial dairy farms in the United States but is not yet widely adopted, possibly due to concerns about the potential for negative effects on cow health. The objective of this study was to compare culture- and algorithm-guided SDCT programs with blanket dry-cow therapy (BDCT) in a multi-site, randomized, natural exposure, non-inferiority trial for the following quarter-level outcomes: antibiotic use at dry-off, dry period intramammary infection (IMI) cure risk, dry period new IMI risk, and IMI risk at 1 to $13 \mathrm{~d}$ in milk (DIM). Two days before planned dry-off, cows in each of 7 herds were randomly allocated to BDCT, culture-guided SDCT (cult-SDCT), or algorithm-guided SDCT (alg-SDCT). At dry-off, BDCT cows received an intramammary antibiotic (500 $\mathrm{mg}$ of ceftiofur hydrochloride) in all 4 quarters. Antibiotic treatments were selectively allocated to quarters of cult-SDCT cows by treating only quarters from which aseptically collected milk samples tested positive on the Minnesota Easy 4Cast plate (University of Minnesota, St. Paul, MN) after 30 to $40 \mathrm{~h}$ of incubation. For alg-SDCT cows, antibiotic treatments were selectively allocated at the cow level, with all quarters receiving antibiotic treatment if the cow had either a Dairy Herd Improvement Association test somatic cell count $>200,000$ cells/ $\mathrm{mL}$ during the current lactation or 2 or more clinical mastitis cases during the current lactation. All quarters of all cows were treated with an internal teat sealant. Intramammary infection status at enrollment and at 1 to 13 DIM was determined using standard bacteriological methods. The effect of treatment group on dry

Received October 9, 2019.

Accepted April 1, 2020.

*Corresponding author: samrowe101@gmail.com period IMI cure, dry period new IMI, and IMI risk at 1 to 13 DIM was determined using generalized linear mixed models (logistic), with marginal standardization to derive risk difference (RD) estimates. Quarter-level antibiotic use at dry-off for each group was BDCT (100\%), cult-SDCT (45\%), and alg-SDCT (45\%). The crude dry period IMI cure risk for all quarters was $87.5 \%$ (818/935), the crude dry period new IMI risk was $20.1 \%(764 / 3,794)$, and the prevalence of IMI at 1 to 13 DIM was $23 \%(961 / 4,173)$. Non-inferiority analysis indicated that culture- and algorithm-guided SDCT approaches performed at least as well as BDCT for dry period IMI cure risk. In addition, the final models indicated that the risks for each of the 3 IMI measures were similar between all 3 treatment groups (i.e., RD estimates and $95 \%$ confidence intervals all close to 0 ). These findings indicate that under the conditions of this trial, culture- and algorithm-guided SDCT can substantially reduce antibiotic use at dry-off without negatively affecting IMI dynamics.

Key words: intramammary infection, dry-cow therapy, selective dry-cow therapy, antibiotic stewardship, onfarm culture

\section{INTRODUCTION}

Control of IMI during the dry period is necessary to optimize udder health in early lactation (Green et al., 2002), and the use of antibiotic treatments at dry-off (dry-cow therapy, DCT) has been shown to facilitate IMI control by curing existing infections and preventing the establishment of new infections (Halasa et al., 2009a,b). At the industry level, widespread implementation of whole-herd DCT or blanket DCT (BDCT) has contributed to declines in SCC and IMI prevalence, especially of Staphylococcus aureus and Streptococcus agalactiae in North America, Europe, and Australasia. However, BDCT contributes to almost one-third of to- 
tal antibiotic use in lactating cows on non-organic dairy farms in the United States (Pol and Ruegg, 2007). Given that consumers have increasing concerns about antibiotic stewardship in food animal production, there is great interest in increasing the adoption of antibioticsparing approaches to DCT.

Selective DCT (SDCT) could be used to strategically allocate antibiotic treatments to individual cows or quarters, and thus reduce antibiotic use at dry-off. This can be achieved via rapid culture systems or by using cow records (typically SCC and clinical mastitis events) in algorithms. Field trials conducted in North America and Europe, using different approaches to SDCT, have demonstrated reductions in antibiotic use at dry-off of 58\% (Kabera et al., 2019), 48\% (McParland et al., 2019), 60\% (Vasquez et al., 2018), 21\% (Cameron et al., 2014), and 85\% (Scherpenzeel et al., 2014). Substantial reductions in antibiotic use at the industry level has also been observed in European countries following nationwide bans on BDCT (Vanhoudt et al., 2018). Despite the potential of SDCT to improve antibiotic stewardship in the US dairy industry, only $10 \%$ of US herds practice SDCT, with the remaining herds practicing BDCT (80\%) or no DCT (10\%; NAHMS, 2014a). This low level of uptake in commercial farms is likely due to perceived risks to cow health and farm profitability, and to logistical challenges surrounding the implementation of SDCT programs. Concerns about potential negative health effects may be in response to the failure of early SDCT approaches, which increased new IMI risk and IMI prevalence postcalving (Berry and Hillerton, 2002; McDougall, 2010; Scherpenzeel et al., 2014). The failure of these SDCT programs may have been due to the use of screening strategies with insufficient diagnostic sensitivity to detect IMI, or failure to use a teat sealant to protect against new IMI during the dry period, or both. However, more recent trials of culture-guided (Cameron et al., 2014; Patel et al., 2017; Kabera et al., 2019) and algorithm-guided (Bradley et al., 2010; Vasquez et al., 2018) SDCT programs, all using teat sealants, found negligible effects on IMI dynamics during the dry period. However, because the aforementioned recent successful SDCT programs conducted in the United States enrolled cows from a single herd, multi-herd studies are warranted to explore the generalizability of their findings. In addition to diagnostic accuracy, other considerations affecting test utility include cost, timeliness, and convenience of implementation. Algorithm-guided SDCT programs, which use previously collected SCC data and clinical mastitis history to indirectly predict a cow's risk of infection at dry-off (Vasquez et al., 2018), will be more convenient and less expensive to implement than culture-guided SDCT programs, which directly detect the presence of
IMI at either the quarter or the cow level (Cameron et al., 2014; Patel et al., 2017). However, few studies have directly compared culture-guided with algorithmguided SDCT programs (tho Seeth et al., 2017). In a separate manuscript, we reported findings from a recent multi-site, randomized, natural exposure study, which found that clinical mastitis and herd removal rates from 1 to 120 DIM and test-day SCC and milk yield were similar among cows randomized to cultureand algorithm-guided SDCT and BDCT (Rowe et al., 2020a). The objective of this study was to compare culture- and algorithm-guided SDCT programs with $\mathrm{BDCT}$ from the same clinical trial for the following quarter-level outcomes: antibiotic use at dry-off, dry period IMI cure risk, dry period new IMI risk, and IMI risk at 1 to 13 DIM. We hypothesized that antibiotic use at dry-off could be reduced in commercial dairy herds in the United States by implementing either an algorithm-guided or a culture-guided SDCT program, without negatively affecting cow health, as identified using measures of dry period IMI dynamics.

\section{MATERIALS AND METHODS}

A randomized, controlled, natural exposure study of SDCT in US dairy herds was conducted between May 2018 and April 2019. The Reporting Guidelines for Randomized Controlled Trials for Livestock and Food Safety (REFLECT; O'Connor et al., 2010) and Reporting of Non-Inferiority and Equivalence Randomized Trials Guidelines (Piaggio et al., 2006) were followed in the reporting of this study. Ethics approval was granted by the University of Minnesota Institutional Animal Care and Use Committee (\#1801-35489A).

\section{Study Herds}

Seven herds were recruited from 5 states (New York: 2 herds; Minnesota: 1 herd; Wisconsin: 1 herd; Iowa: 1 herd; and California: 2 herds) from May to July 2018. Herds were selected because they had a working relationship with the University of Minnesota, Cornell University, Iowa State University, DairyExperts Inc., or Dairy Health and Management Services, had a herd size sufficiently large to dry off 15 cows per week, had an average bulk milk SCC less than 250,000 cells/mL during the previous 12 mo, were on a monthly DHIA testing schedule (i.e., individual cow SCC and milk weight measurements), and routinely and consistently recorded clinical mastitis and culling events. The bulk tank SCC threshold was used as an inclusion criterion, as it has been suggested by mastitis experts that herds with lower bulk milk SCC are more likely to benefit from SDCT (Bradley et al., 2018). 


\section{Cow Enrollment Visit}

Phases of cow enrollment and dry-off treatments are summarized in Figure 1. Study technicians visited herds each week to enroll cows $2 \mathrm{~d}$ before the planned dry-off date. Cows were eligible for enrollment if they had 4 functional quarters, an expected dry period length of 30 to $90 \mathrm{~d}$, no recent antibiotic or anti-inflammatory treatment (within $14 \mathrm{~d}$ ), no clinical mastitis (i.e., no visible abnormalities present in foremilk; no heat, erythema, or pain detected upon palpation of the udder), and not a high locomotion score [must be $<4$ on the 5 -point scoring system proposed by Sprecher et al. (1997)] or poor BCS [must be $>1$ on the 5-point dairy scoring system proposed by Edmonson et al. (1989)]. Following enrollment, duplicate aseptic quarter-milk samples were collected from enrolled cows according to National Mastitis Council guidelines (NMC, 2017). Briefly, after milking staff performed their usual pre-milking teat disinfection routine, study technicians wearing clean disposable gloves scrubbed teat ends with $70 \%$ isopropyl alcohol-soaked gauze swabs, discarded 3 squirts of foremilk, and sampled approximately 20 to $30 \mathrm{~mL}$ of milk into 2 sterile $60-\mathrm{mL}$ vials. Samples were immediately chilled on ice and transported back to the site laboratory.

Cows were block-randomized (block size $=18$; number of unique blocks $=11$ ) to 1 of 3 treatment groups by study technicians: BDCT, culture-based SDCT (cultSDCT), or algorithm-based SDCT (alg-SDCT). The sequence of treatment groups within each block was determined using a random number generator in Excel (version 16; Microsoft Corp., Redmond, WA), which was printed onto the set of enrollment forms that were used at all sites. Randomization was stratified by herd and enrollment date. Following enrollment, cows were milked by farm staff according to each farm's usual routine until the day of dry-off. On 2 farms (herds 5 and 6), cows were milked once daily until dry-off. For herd 6, a commercial external teat sealant (T-Hexx Dry, Huvepharma, St. Louis, MO) was applied to the teats after each milking. Other herds were milked twice or three times daily until dry-off.

\section{Rapid Culture}

Upon arrival at the site laboratory, 1 of each duplicate of the quarter milk samples from cows in the cult-SDCT group were plated onto the Minnesota Easy 4 Cast plate (University of Minnesota, St. Paul, MN) using sterile cotton-tipped swabs, and incubated at $37 \pm 2^{\circ} \mathrm{C}$ for 30 to $40 \mathrm{~h}$. All milk samples, including those used for inoculating the rapid culture plates, were stored at $-20^{\circ} \mathrm{C}$ for later laboratory analysis as will be described. Minnesota Easy 4Cast plates were read by a study technician the morning of the dry-off visit, and quarter-level results recorded as "growth" or "no growth." Samples with growth patterns suggestive of contamination (i.e., numerous independent isolates) were classified as growth.

\section{Dry-Off Visit}

Dry-off was conducted $2 \mathrm{~d}$ after enrollment. All quarters of BDCT cows were treated with an intramammary antibiotic (500 mg of ceftiofur hydrochloride, Spectramast DC, Zoetis, Parsippany, NJ). In cult-SDCT cows, individual quarters were treated with antibiotics if any growth was observed on the Minnesota Easy 4Cast plate. Cows in alg-SDCT had all 4 quarters treated with antibiotics if they met any of the following criteria for treatment: $\geq 2$ cases of clinical mastitis during lactation or any DHIA test with SCC $>200,000$ cells $/ \mathrm{mL}$ during lactation. This algorithm was slightly modified from an earlier algorithm described by Vasquez et al. (2018) and was intended to identify cows most likely infected with major pathogens by using both SCC and clinical mastitis records for the current lactation. All quarters of all cows were infused with an internal teat sealant (ITS) containing bismuth subnitrate (Orbeseal, Zoetis). Antibiotic and ITS infusions were administered after the final milking in the following fashion: study technicians, who were wearing clean disposable gloves, scrubbed teat ends with $70 \%$ isopropyl alcohol-soaked gauze swabs for at least $5 \mathrm{~s}$ before the antibiotic treatment was infused into the mammary gland and again before ITS was infused into the teat cistern. A partial insertion technique was used for both antibiotic and ITS treatments. Cows that received incorrect antibiotic treatments were either excluded or reassigned to the BDCT group. Consequently, analysis was conducted on an "as-treated" basis, which is preferable to "intention to treat" in non-inferiority designs (Piaggio et al., 2006). All procedures were conducted by trained technicians.

\section{Follow-Up During the Dry Period and Postcalving}

Clinical diseases during the dry period and early lactation were detected and recorded by farm staff, who were masked to treatment status of cows and laboratory culture results. On 2 farms, the herd manager was granted access to antibiotic treatment records, which could have allowed them to indirectly determine treatment status of cows. A companion manuscript reports clinical mastitis events, culling and death events, SCC, and milk yield outcomes during the dry period and following lactation (Rowe et al., 2020b). Duplicate aseptic 


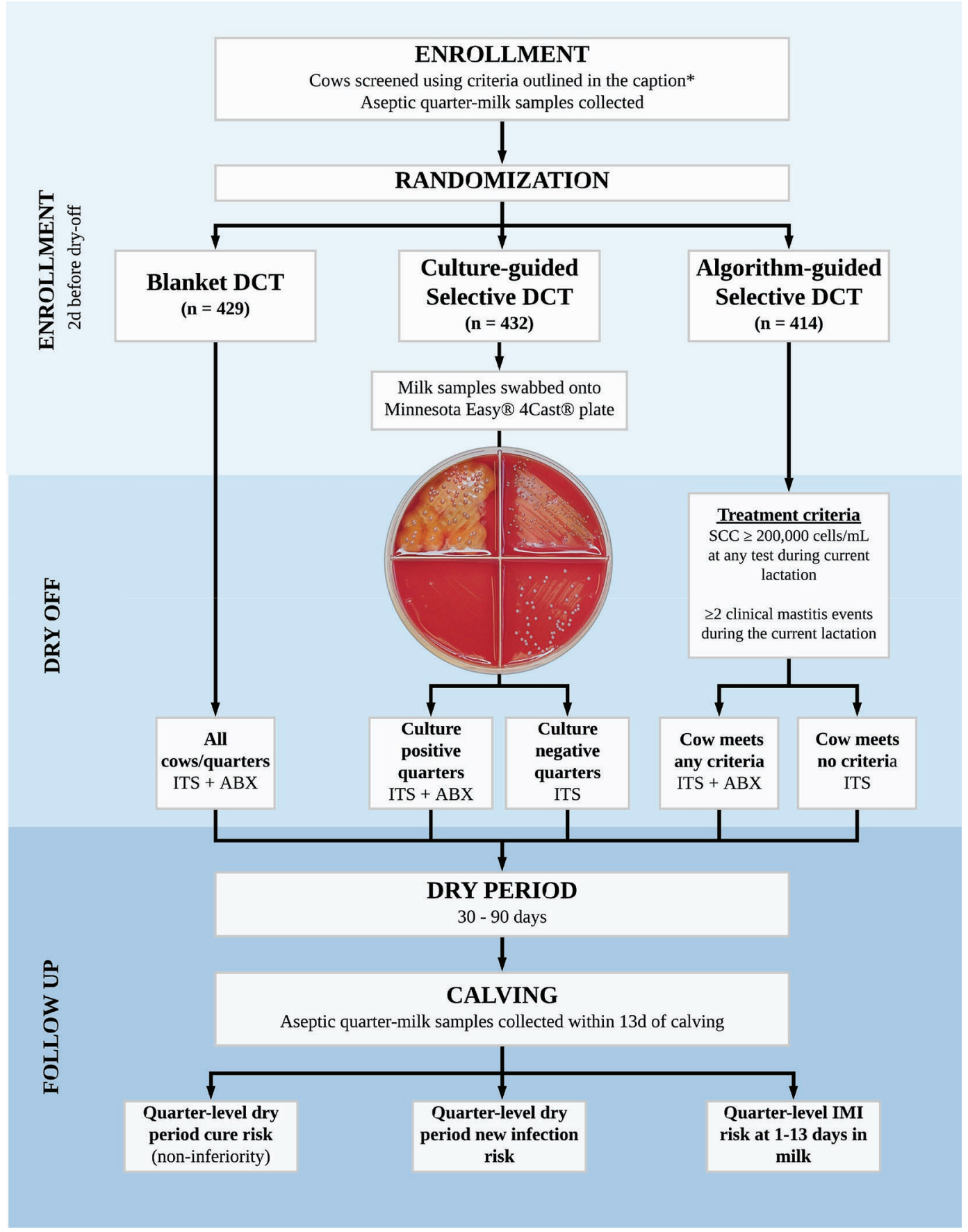

Figure 1. Outline of how treatments were allocated to cows in each treatment group, and the data collected to establish outcomes. DCT $=$ dry cow therapy; ITS = internal teat sealant (Orbeseal, Zoetis, Parsippany, NJ); ABX = antibiotic treatment with 500 mg of ceftiofur hydrochloride (Spectramast DC, Zoetis). Minnesota Easy 4Cast plate used for culturing (University of Minnesota, St. Paul, MN). *To be enrolled, cows needed to have 4 functional quarters, an expected dry period length of 30 to $90 \mathrm{~d}$, no recent antibiotic or anti-inflammatory treatment (within $14 \mathrm{~d}$ ), no clinical mastitis, and not be lame or in poor body condition.

quarter milk samples were collected by a study technician at 1 to 13 DIM, using the same methods described for the enrollment sampling. Samples were immediately chilled on ice and stored at $-20^{\circ} \mathrm{C}$ for later laboratory analysis.

\section{Microbiological Culture of Milk Samples}

Milk samples were stored at $-20^{\circ} \mathrm{C}$ for 1 to $7 \mathrm{~d}$ before being cultured. The IMI status of each quarter at enrollment and from 1 to 13 DIM was determined us- 
ing standard bacteriological methods. Milk culture was completed at the regional laboratory (Minnesota, New York, Iowa, or California) using culture methods that were standardized across the 4 laboratories. Laboratory staff were masked to the treatment group. On the day of testing, milk samples were thawed at room temperature, homogenized by gentle inversion, and plated onto trypticase soy agar with 5\% sheep blood. Agar plates were inoculated with 1 loopfull (approximately $10 \mu \mathrm{L}$ ) of sample, using disposable plastic loops, and incubated in aerobic conditions at $37 \pm 2^{\circ} \mathrm{C}$ for 42 to $48 \mathrm{~h}$. Only 1 sample from each quarter was cultured, unless the first sample was contaminated. Samples were classified as contaminated if 3 or more distinct microbial isolates were recovered. This meant that for cult-SDCT cows, the sample used for inoculating the Minnesota Easy 4 Cast plate was used a second time for laboratory culture when the other sample was contaminated. Care was taken to avoid contamination of milk samples when they were used for testing. At the regional labs in Minnesota, New York, and Iowa, all isolates were identified using a MALDI-TOF mass spectrometer (Microflex; Bruker Daltonics Inc., Billerica, MA). Peaks produced by each isolate were analyzed using the MALDI-TOF Biotyper reference library (Microflex). The confidence level for each diagnosis reported by the software was used in the following fashion: $>2.0$ : species level diagnosis recorded; 1.8 to 2 : genus level diagnosis recorded; $<1.8$ : MALDI-TOF diagnosis not recorded and traditional identification methods used. Traditional identification methods included colony morphology, catalase reaction, Gram stain, and cytology. Because the California laboratory did not have MALDI-TOF available for isolate identification, isolates identified there were stored in glycerol vials at $-80^{\circ} \mathrm{C}$ before submitting them to the Minnesota laboratory. Isolates sent to Minnesota were cultured on trypticase soy agar with $5 \%$ sheep blood in aerobic conditions and incubated at $37 \pm 2{ }^{\circ} \mathrm{C}$ for $24 \mathrm{~h}$ before being identified using the methods described earlier. If the culture from a glycerol vial failed to yield a single isolate (i.e., no growth or 2 or more isolates), then the original milk sample was cultured again in California, and the isolate was resubmitted. If no pathogen was isolated on the second milk culture at the California laboratory, the quarter was excluded from analysis. To improve the specificity of IMI classification (i.e., reduce false positives), NAS isolates with fewer than 2 colonies $(<200 \mathrm{cfu} / \mathrm{mL})$ and Bacillus spp. isolates with fewer than 5 colonies $(<500 \mathrm{cfu} / \mathrm{mL})$ were reclassified as "no growth" and the quarter considered uninfected (Dohoo et al., 2011b). This adjustment was made because poor specificity is a more potent source of biased measures of association than poor sensitivity (Haine et al., 2018).

\section{Statistical Analysis}

Sample Size Calculation. Sample size was calculated to enable non-inferiority analysis of dry period IMI cure risk. We assumed that $20 \%$ of quarters would be infected at dry-off and that the dry period cure risk in BDCT quarters would be $88 \%$ (Arruda et al., 2013; Johnson et al., 2016). The margin of non-inferiority, $\alpha$, and power were set at $-10 \%, 2.5 \%$, and $80 \%$, respectively. According to these assumptions, the sample size required was multiplied by 1.3 to account for clustering within the data and to account for missing cure statuses in $10 \%$ of quarters, due to contamination of milk samples or failure to collect a milk sample within $13 \mathrm{~d}$ of calving.

Variable Management. Cow- and quarter-level enrollment and dry-off treatment records, herd demographic information, and laboratory findings were recorded in spreadsheets (Google Sheets; Google LLC, Mountain View, CA). Disease events (clinical mastitis, culling, and death) and SCC and milk yield records from monthly DHIA testing were extracted from electronic farm records. Data were imported into the R Statistical Programming Environment (R Core Team, 2018) for merging and cleaning. Analysis was conducted in $\mathrm{R}$ and STATA (version 15; StataCorp, College Station, TX). The analysis log can be found at https://samrowe101 .github.io/SDCT-2019/QTRoutcomes.html. No imputation methods were used for predictor variables, as very few data were missing. Normality of continuous variables was assessed by visualizing normal quantilequantile plots. All SCC measures (SCC peak during previous lactation and SCC at last DHIA test) were $\log _{\mathrm{e}}$ transformed for analysis. Cows and quarters were retrospectively excluded from analysis if they failed to meet inclusion criteria. Consequently, cows with a dry period outside of the 30- to 90-d range, including cows that failed to calve or that were culled during the dry period, were excluded from analysis. Furthermore, treatment records were used to retrospectively exclude quarters from cows with antibiotic treatment during the 14-d period before milk sampling (at enrollment or postcalving). Quarters without a determined IMI status, mostly due to contamination of milk samples, were not imputed and thus were excluded from analysis (Dohoo et al., 2016).

Effect of SDCT on Quarter-Level Dry Period IMI Dynamics. Intramammary infection status at enrollment and postcalving was used to determine dry period infection dynamics, including IMI cure and new IMI. Consequently, quarters missing an IMI status at 1 or both periods were not assigned a value for dry period IMI cure or new IMI. Only quarters with an IMI at the enrollment sample were considered at risk 
for a dry period IMI cure. Dry period IMI cure cases were defined as a quarter with a species-level IMI present at enrollment that was not isolated in the postcalving sample. All quarters were considered at risk for developing a dry period new IMI. Dry period new IMI cases were defined as a quarter with a specieslevel IMI at calving that was not originally present in the enrollment sample. For example, a quarter with a Staphylococcus chromogenes IMI at enrollment and no growth at 1 to 13 DIM would be coded as a dry period IMI cure $=1$, and dry period new $\mathrm{IMI}=0$. A quarter with a Staphylococcus chromogenes IMI at enrollment and a Staphylococcus haemolyticus IMI at 1 to 13 DIM would be coded as a dry period IMI cure $=1$, and a dry period new $\mathrm{IMI}=1$. Isolates were matched at the genus level if the species was not known. For example, a quarter with a Staphylococcus chromogenes IMI at enrollment and a Staphylococcus spp. IMI at 1 to 13 DIM would be coded as a dry period IMI cure $=0$, and dry period new IMI $=0$.

Unconditional relative risk estimates for the relationship between explanatory variables of interest and IMI at enrollment, IMI at 1 to 13 DIM, dry period cure risk, and dry period new IMI risk were calculated using generalized linear models (binomial family, log link; "log-binomial model"). Potential cow-level confounders investigated included age at enrollment (mo), parity at enrollment $(1,2, \geq 3)$, milk yield $(\mathrm{kg})$ and $\log _{\mathrm{e}} \mathrm{SCC}(\mathrm{log}$ cells $\times 10^{3} / \mathrm{mL}$ ) at the most recent herd test before enrollment, peak $\log _{\mathrm{e}} \mathrm{SCC}$ during the lactation of enrollment, any clinical mastitis events during the lactation of enrollment (dichotomous), DIM at dry-off (per $10 \mathrm{~d}$ ), and DIM at postcalving milk sample (d). In addition, quarter-level IMI at enrollment (dichotomous) was considered a potential confounder for the relationship between treatment group and dry period new IMI and IMI risk postcalving.

The final multivariable model for the effect of treatment group on quarter-level IMI outcomes (dry period cure risk, dry period new IMI risk, and IMI risk at 1 to 13 DIM) was determined using generalized linear mixed models (binomial family, logit link; i.e., logistic regression) using the following model-building strategy. A directed acyclic graph was drawn for each model, to identify potential confounders. Correlations between potential confounders were determined using Pearson correlation coefficient and Kendall's tau for normally and non-normally distributed continuous variables, respectively. Highly correlated variables $(>0.7)$ were not offered to the same model, with the more suitable variable chosen based on missing values, reliability of measurement, or biological plausibility. Potential confounders were simultaneously offered to the initial model. Following this, biologically plausible effect measure modification on the multiplicative scale was evaluated by fitting interaction terms as fixed effects. For interaction terms with Wald tests at $P<0.05$, effect estimates were stratified by the effect-modifying variable and, if biologically relevant, included in the final model. Interaction terms were removed from the model if they had Wald tests at $P>0.05$ or if they did not add subjective explanatory value to the model. Following this, covariates (potential confounders) were removed from the model one at a time, and replaced back into the model if removal changed the effect estimate by more than $10 \%$ (Greenland and Pearce, 2015). All models included random intercepts for cow and herd, to account for the clustering of quarters within cows and of cows within herds.

Risk difference (RD) estimates for the effect of treatment on quarter-level dry period IMI dynamics were derived from the final logistic regression model using the margins command in Stata, a process called "marginal standardization" (Muller and MacLehose, 2014). A non-inferiority hypothesis test was used to evaluate the effect of SDCT on dry period IMI cure risk, using the confidence interval approach, with an a priori margin of non-inferiority specified at $-10 \%$. Therefore, the null hypothesis was that cure risk in either SDCT group (cult-SDCT or alg-SDCT) was at least $10 \%$ lower than in BDCT quarters. The 2-sided, $95 \%$ confidence interval for the risk difference was used to conduct the hypothesis test, such that if the lower limit of the confidence interval was greater (i.e., "better") than the a priori margin of non-inferiority, then the experimental group (either SDCT group) would be considered non-inferior to or "at least as good" as the positive control group (BDCT). We chose to conduct a non-inferiority test only for dry period IMI cures because this was the primary outcome of interest in our study. Additionally, because the original sample size calculations were based on using a non-inferiority test for dry period IMI cures, it is possible that statistical power would not be sufficient to enable non-inferiority analysis for other outcomes. No superiority hypothesis tests were conducted to evaluate the effect of SDCT group on measures of udder health (Wasserstein and Lazar, 2016).

\section{RESULTS}

\section{Enrollment}

Demographic information about the 7 study herds can be found in Table 1. All herds were predominantly Holstein cows, except for herd 3 , which was predominantly Holstein-Jersey cross. Herd size ranged from 850 to 5,700 milking cows, and bulk milk SCC before 
enrollment ranged from 90,000 to 230,000 cells/mL. All herds routinely practiced pre- and post-milking teat disinfection as part of their milking routine and used a registered Escherichia coli vaccine as part of their mastitis-control strategy. In 5 herds, lactating cows were managed in freestall barns with sand $(\mathrm{n}=3)$ or recycled manure solids $(\mathrm{n}=2)$ bedding. The remaining 2 herds used a combination of freestalls and compostbedded packs. The dry-cow housing facilities used were deep-bedded sand freestalls $(\mathrm{n}=4$ herds), recycled manure dry-lots $(\mathrm{n}=2)$, and compost-bedded pack (n $=1$ ). At enrollment, cows were randomly allocated to BDCT ( $\mathrm{n}=429,1,716$ quarters), cult-SDCT $(\mathrm{n}=432$, 1,728 quarters), or alg-SDCT ( $\mathrm{n}=414,1,656$ quarters) groups. Demographic information about the enrolled cows in each treatment group can be found in Table 2 . Median age at enrollment (skewed distribution) was 45 mo (interquartile range: 34 to 56), mean DIM at dry-off (normally distributed) was $325(\mathrm{SD}=46)$, and mean milk yield at the most recent DHIA test before dry-off (normally distributed) was $27.3 \mathrm{~kg}(\mathrm{SD}=8.7)$. The proportions of cows of parity 1,2 , and $\geq 3$ at enrollment were 42,30 , and $28 \%$, and the proportion of cows at enrollment that had experienced at least 1 clinical mastitis event during the lactation of enrollment was $14 \%$.

\section{Losses to Follow-Up}

Losses to follow-up at the cow and quarter levels during each phase of the study are outlined in Figure 2. Three enrolled cows were retrospectively excluded because of recent $(<14 \mathrm{~d})$ antibiotic treatments before enrollment. Two cows from the cult-SDCT group were reassigned to the BDCT group due to study technicians accidentally treating quarters that did not have bacterial growth on the Minnesota Easy 4Cast plate. After cows were reassigned, they had all 4 quarters treated with antibiotics, regardless of culture results.

At dry-off (2 d after enrollment), 29 cows were removed from the study by study technicians because they did not meet the inclusion criteria, mostly due to being found non-pregnant and thus unable to have a dry period less than $90 \mathrm{~d}$. Consequently, the number of cows dried off in each group was 417 in BDCT, 422 in cult-SDCT, and 404 in alg-SDCT. Demographics for study herds and treatment groups at this stage of enrollment are compared in Tables 1 and 2, respectively. During the dry period, 11 cows died or were culled from the BDCT $(\mathrm{n}=5)$, cult-SDCT $(\mathrm{n}=1)$, and alg-SDCT $(\mathrm{n}=5)$ groups. Of these, 3 deaths $(2$ in BDCT and 1 in alg-SDCT) occurred in the 14-d period after dry-off. The remaining deaths or culls occurred 21 to $77 \mathrm{~d}$ after dry-off. No mastitis cases were recorded for culled or dead animals during the dry period. An additional 17 and 4 cows were retrospectively excluded from the study because of short $(<30 \mathrm{~d})$ or long $(>90 \mathrm{~d})$ dry periods, respectively. In total, 22,22 , and 20 cows from BDCT, cult-SDCT, and alg-SDCT groups, respectively, were lost to follow-up between enrollment and calving. An additional 35 cows $(\mathrm{BDCT}=15$, cult-SDCT $=12$, alg$\mathrm{SDCT}=8)$ were excluded from analysis because of recent $(<14 \mathrm{~d})$ antibiotic treatment before milk sampling following calving. Six of these cows had been treated for mastitis. The remaining antibiotic treatments were for reproductive disorders, trauma, and lameness. Quarters from 65 cows $(\mathrm{BDCT}=19$, cult-SDCT $=19$, alg-SDCT $=27)$ were excluded due to failure to collect a milk sample within $13 \mathrm{~d}$ of calving. An additional $462(\mathrm{BDCT}=172 / 1,716$, cult-SDCT $=150 / 1,728$, alg-SDCT $=140 / 1,656)$ and $271(\mathrm{BDCT}=100 / 1,716$, cult-SDCT $=90 / 1,728$, alg-SDCT $=81 / 1,656)$ quarters were contaminated at the enrollment and postcalving samplings, respectively. Consequently, the number of quarters considered at risk of having an IMI at 1 to 13 DIM for each group were 1,392 in BDCT, 1,426 in cult-SDCT, and 1,355 in alg-SDCT.

\section{Antibiotic Use}

Antibiotic use at the quarter level for each treatment group were 1,668 for BDCT (out of 1,668; 100\%), 752 for cult-SDCT (out of 1,688; 44.5\%), and 724 for algSDCT (out of 1,$616 ; 44.8 \%$ ) when considering all cows that were dried off as part of the trial. The proportion of quarters treated per farm ranged from 31.9 to $61.8 \%$ for cult-SDCT quarters and from 18.9 to $68.4 \%$ in algSDCT quarters.

\section{IMI at Enrollment and at 1 to 13 DIM}

The quarter-level prevalence of IMI at enrollment was $25.4 \%(1,078 / 4,242$; Table 3$)$. Of the 1,144 cows with a valid culture result at dry-off, $670(59 \%)$ had at least 1 infected quarter. Of the cows with at least 1 infected quarter at enrollment and a full set of culture results (i.e., none excluded for contamination; $\mathrm{n}=$ $519)$, the number of quarters infected per cow were 275 with 1 (53.0\%), 159 with 2 (30.6\%), 67 with 3 (12.9\%), and 18 with $4(3.5 \%)$. The quarter-level prevalence of IMI in BDCT, cult-SDCT, and alg-SDCT groups were $25.1 \%(350 / 1,396), 25.0 \%(360 / 1,442)$, and $25.3 \%$ $(355 / 1,404)$, respectively. The overall quarter-level prevalence of IMI caused by pathogen groups were $14.8 \%$ NAS, $0.3 \%$ Staphylococcus aureus, $2.2 \%$ Streptococcus and strep-like organisms (SSLO), $7.9 \%$ other gram-positive bacteria, $1.5 \%$ gram-negative bacteria, and $0.1 \%$ other pathogens. Note that these prevalences do not sum to the overall prevalence of IMI (25.4\%) 
Rowe et al.: SELECTIVE DRY COW THERAPY IN US DAIRY HERDS: QUARTER-LEVEL OUTCOMES

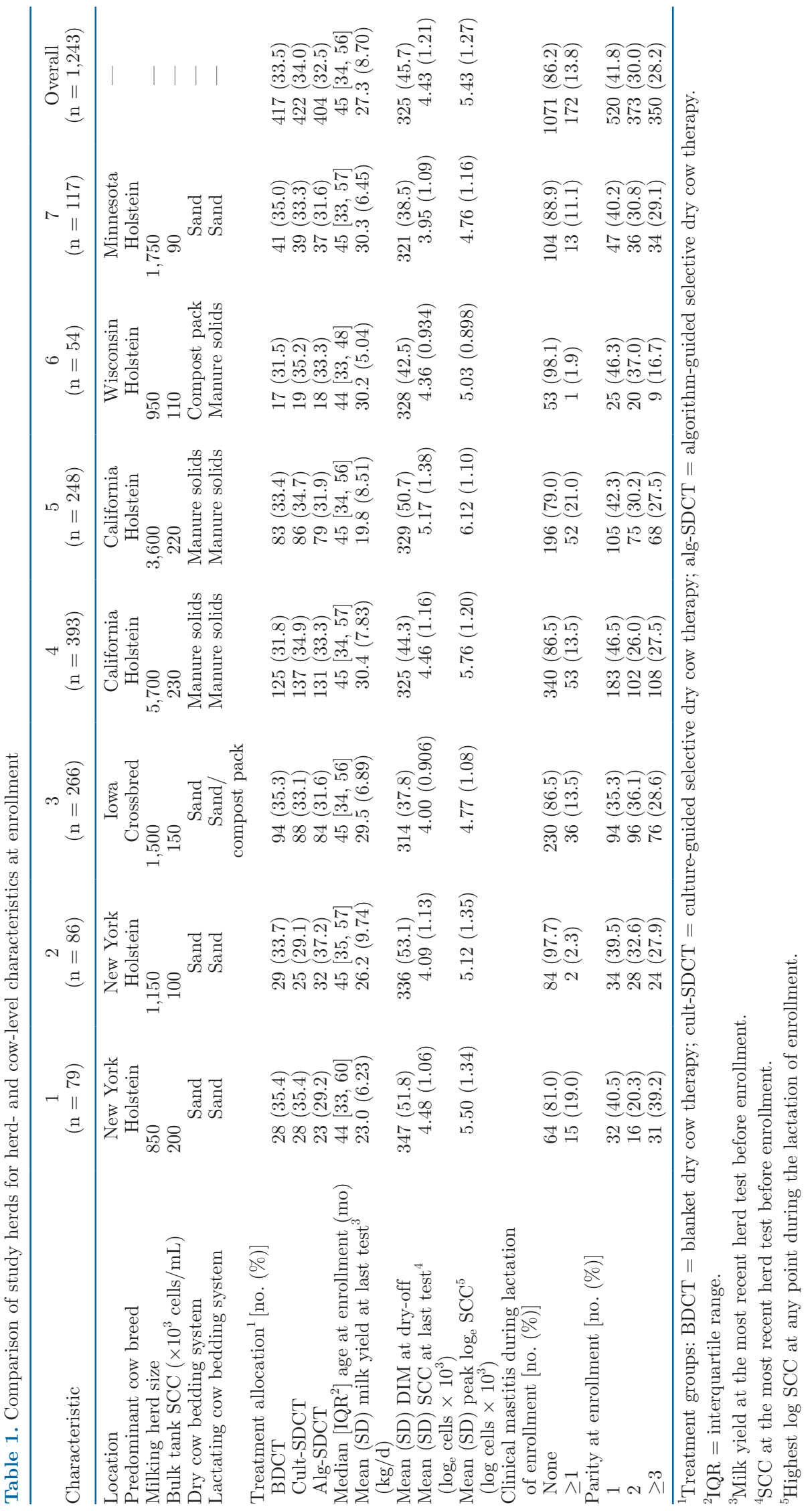


Table 2. Comparison of treatment groups ${ }^{1}$ for cow-level characteristics at enrollment

\begin{tabular}{|c|c|c|c|c|}
\hline Characteristic & $\begin{array}{c}\mathrm{BDCT} \\
(\mathrm{n}=417)\end{array}$ & $\begin{array}{c}\text { Cult-SDCT } \\
(\mathrm{n}=422)\end{array}$ & $\begin{array}{l}\text { Alg-SDCT } \\
(\mathrm{n}=404)\end{array}$ & $\begin{array}{c}\text { Overall } \\
(\mathrm{n}=1,243)\end{array}$ \\
\hline Median $\left[\mathrm{IQR}^{2}\right]$ age at enrollment $(\mathrm{mo})$ & $45[34,57]$ & $44[34,57]$ & $45[34,56]$ & $45[34,56]$ \\
\hline Mean (SD) milk yield at last test ${ }^{3}(\mathrm{~kg} / \mathrm{d})$ & $26.8(8.87)$ & $27.8(8.81)$ & $27.3(8.38)$ & $27.3(8.70)$ \\
\hline Mean (SD) SCC at last test ${ }^{4}\left(\log _{\mathrm{e}}\right.$ cells $\times 1,000$ per $\left.\mathrm{mL}\right)$ & $4.45(1.21)$ & $4.39(1.22)$ & $4.45(1.20)$ & $4.43(1.21)$ \\
\hline Mean (SD) peak log $\mathrm{SCC}^{5}\left(\log _{\mathrm{e}}\right.$ cells $\times 1,000$ per $\left.\mathrm{mL}\right)$ & $5.39(1.31)$ & $5.51(1.23)$ & $5.40(1.28)$ & $5.43(1.27)$ \\
\hline \multicolumn{5}{|l|}{ Clinical mastitis during lactation of enrollment [no. (\%)] } \\
\hline \multicolumn{5}{|l|}{ Parity at enrollment [no. (\%)] } \\
\hline 1 & $163(39.1)$ & $188(44.5)$ & $169(41.8)$ & $520(41.8)$ \\
\hline 2 & $135(32.4)$ & $111(26.3)$ & $127(31.4)$ & $373(30.0)$ \\
\hline$\geq 3$ & $119(28.5)$ & $123(29.2)$ & $108(26.8)$ & $350(28.2)$ \\
\hline
\end{tabular}

${ }^{1}$ Treatment groups: BDCT $=$ blanket dry cow therapy; cult-SDCT $=$ culture-guided selective dry cow therapy; alg-SDCT $=$ algorithm-guided selective dry cow therapy.

${ }^{2} \mathrm{IQR}=$ interquartile range.

${ }^{3}$ Milk yield at the most recent herd test before enrollment.

${ }^{4} \mathrm{SCC}$ at the most recent herd test before enrollment.

${ }^{5}$ Highest $\log _{\mathrm{e}} \mathrm{SCC}$ at any point during the lactation of enrollment.

because some quarters were infected with 2 pathogens $(\mathrm{n}=91)$. The most common bacterial species was Staphylococcus chromogenes, which infected $8.0 \%$ of quarters. Other common causes of IMI at enrollment included Staphylococcus spp. (4.0\%), Corynebacterium spp. (4.0\%), Micrococcus spp. (1.5\%), Staphylococcus haemolyticus (1.1\%), and Bacillus spp. (0.9\%). Staphy-

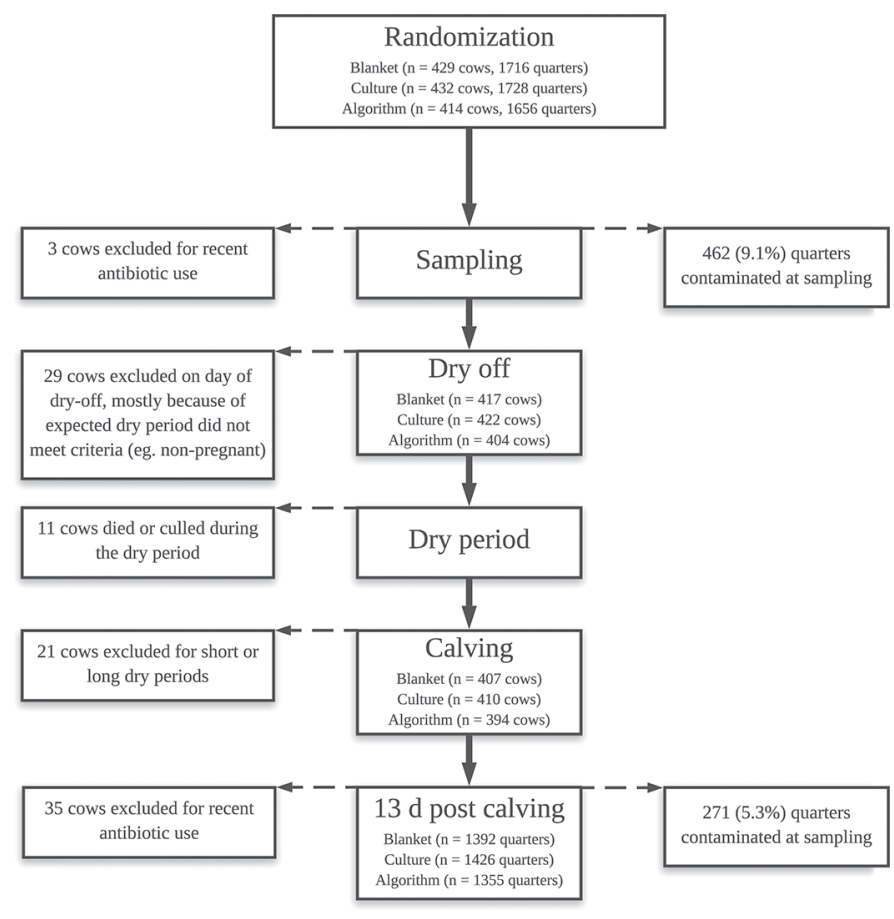

Figure 2. Description of losses to follow-up during each stage of the trial. Excluded cows (e.g., for recent antibiotic use) are shown to the left side of each phase of the study, and excluded quarters (mostly due to contamination) are shown to the right side. lococcus aureus (0.3\%), Streptococcus uberis (0.1\%), and coliforms $(0.6 \%)$ were uncommon causes of IMI.

The quarter-level prevalence of IMI at 1 to 13 DIM was $23.0 \%(961 / 4,173$; Table 4$)$. The prevalences were similar in BDCT $(22.8 \%, 317 / 1,392)$, cult-SDCT $(23.9 \%, 341 / 1,426)$, and alg-SDCT quarters $(22.4 \%$, $303 / 1,355)$. Unconditional risk ratio estimates for various predictors of IMI at enrollment and at 1 to 13 DIM are reported in Table 5 . The final model for IMI risk at 1 to 13 DIM is shown in Table 6. Adjusted risks and $\mathrm{RD}$ estimates for IMI at 1 to $13 \mathrm{DIM}$ were $17.2 \%$ for BDCT, $17.5 \%$ for cult-SDCT $(\mathrm{RD}=+0.3 \%, 95 \% \mathrm{CI}$ : $-2.4,3.1 \%)$, and $16.7 \%$ for alg-SDCT $(\mathrm{RD}=-0.5 \%$, $95 \%$ CI: $-3.2,2.3 \%)$. The intraclass correlation coefficients for clustering of quarters within cows and cows within herds were 0.31 and 0.16 . The overall quarterlevel prevalence of IMI caused by pathogen groups were $13.0 \%$ NAS, 0.1\% Staphylococcus aureus, 1.4\% SSLO, $7.9 \%$ other gram-positive bacteria, $1.9 \%$ gram-negative bacteria, and $0.3 \%$ other pathogens. Note that these prevalences do not sum to the overall prevalence of IMI $(23.0 \%)$ because some quarters were infected with 2 pathogens $(\mathrm{n}=107)$. Like the samples collected at dry-off, the most common bacterial species was Staphylococcus chromogenes, which infected $4.6 \%$ of quarters. Other common causes of IMI included Staphylococcus spp. (4.7\%), Staphylococcus sciuri (3.1\%), Bacillus spp. (3.1\%), and Corynebacterium spp. (2.5\%).

\section{Effect of SDCT on Dry Period IMI Cure and New IMI Risk}

Unconditional risk ratio estimates for various predictors of dry period IMI cure and new IMI risk are report- 
Table 3. Quarter-level prevalence of IMI in 1,275 enrolled cows, 2 d before planned dry-off date, stratified by treatment group ${ }^{1}$

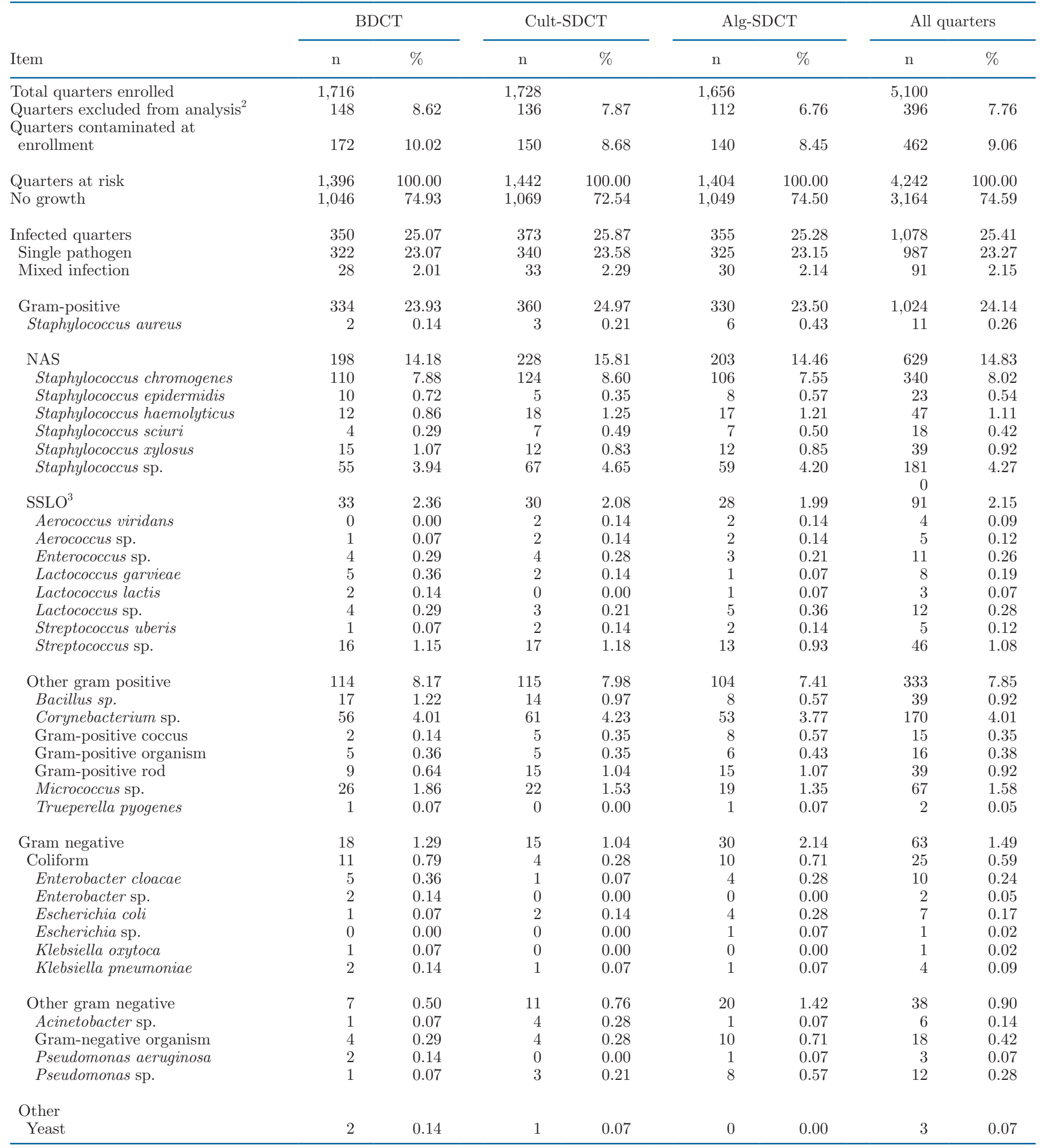

${ }^{1}$ Treatment groups: BDCT $=$ blanket dry cow therapy; cult-SDCT $=$ culture-guided selective dry cow therapy; alg-SDCT $=$ algorithm-guided selective dry cow therapy.

${ }^{2}$ Quarters from cows that were excluded during the trial or retrospectively. Most exclusions were due to failure of subjects to calve 30 to $90 \mathrm{~d}$ after planned dry-off or antibiotic treatment less than $15 \mathrm{~d}$ before sampling.

${ }^{3}$ Streptococcus spp. and strep-like organisms. 
Table 4. Quarter-level prevalence of IMI in 1,275 enrolled cows at 1 to $13 \mathrm{~d}$ after calving, stratified by treatment group ${ }^{1}$

\begin{tabular}{|c|c|c|c|c|c|c|c|c|}
\hline Item & \multicolumn{2}{|c|}{ BDCT } & \multicolumn{2}{|c|}{ Cult-SDCT } & \multicolumn{2}{|c|}{ Alg-SDCT } & \multicolumn{2}{|c|}{ All quarters } \\
\hline Total quarters enrolled & 1,716 & & 1,728 & & 1,656 & & 5,100 & \\
\hline $\begin{array}{l}\text { Quarters contaminated at } \\
1-13 \text { DIM }\end{array}$ & 100 & 5.83 & 90 & 5.21 & 81 & 4.83 & 271 & 5.31 \\
\hline Infected quarters & 317 & 22.77 & 341 & 23.91 & 303 & 22.36 & 961 & 23.03 \\
\hline Single pathogen & 272 & 19.54 & 311 & 21.81 & 271 & 20.00 & 854 & 20.46 \\
\hline Mixed infection & 45 & 3.23 & 30 & 2.10 & 32 & 2.36 & 107 & 2.56 \\
\hline Gram positive & 289 & 20.76 & 311 & 21.81 & 286 & 21.11 & 886 & 21.23 \\
\hline Staphylococcus aureus & 2 & 0.14 & 0 & 0.00 & 0 & 0.00 & 2 & 0.05 \\
\hline Staphylococcus sciuri & 44 & 3.16 & 43 & 3.02 & 41 & 3.03 & 128 & 3.07 \\
\hline Staphylococcus xylosus & 1 & 0.07 & 6 & 0.42 & 6 & 0.44 & 13 & 0.31 \\
\hline Staphylococcus sp. & 64 & 4.60 & 71 & 4.98 & 67 & 4.94 & 202 & 4.84 \\
\hline $\mathrm{SSLO}^{3}$ & 17 & 1.22 & 17 & 1.19 & 23 & 1.70 & 57 & 1.37 \\
\hline Aerococcus viridans & 2 & 0.14 & 1 & 0.07 & 2 & 0.15 & 5 & 0.12 \\
\hline Aerococcus sp. & 1 & 0.07 & 2 & 0.14 & 0 & 0.00 & 3 & 0.07 \\
\hline Enterococcus sp. & 5 & 0.36 & 4 & 0.28 & 3 & 0.22 & 12 & 0.29 \\
\hline Lactococcus garvieae & 2 & 0.14 & 2 & 0.14 & 2 & 0.15 & 6 & 0.14 \\
\hline Lactococcus lactis & 0 & 0.00 & 1 & 0.07 & 0 & 0.00 & 1 & 0.02 \\
\hline Lactococcus sp. & 2 & 0.14 & 0 & 0.00 & 4 & 0.30 & 6 & 0.14 \\
\hline Streptococcus dysgalactiae & 0 & 0.00 & 2 & 0.14 & 2 & 0.15 & 4 & 0.10 \\
\hline Streptococcus uberis & 1 & 0.07 & 1 & 0.07 & 1 & 0.07 & 3 & 0.07 \\
\hline Streptococcus sp. & 7 & 0.50 & 7 & 0.49 & 11 & 0.81 & 25 & 0.60 \\
\hline Gram negative & 33 & 2.37 & 28 & 1.96 & 18 & 1.33 & 79 & 1.89 \\
\hline Coliform & 6 & 0.43 & 10 & 0.70 & 2 & 0.15 & 18 & 0.43 \\
\hline Enterobacter cloacae & 2 & 0.14 & 2 & 0.14 & 1 & 0.07 & 5 & 0.12 \\
\hline Escherichia coli & 3 & 0.22 & 5 & 0.35 & 1 & 0.07 & 9 & 0.22 \\
\hline Klebsiella oxytoca & 1 & 0.07 & 2 & 0.14 & 0 & 0.00 & 3 & 0.07 \\
\hline Klebsiella pneumoniae & 0 & 0.00 & 1 & 0.07 & 0 & 0.00 & 1 & 0.02 \\
\hline Other gram negative & 27 & 1.94 & 18 & 1.26 & 16 & 1.18 & 61 & 1.46 \\
\hline Acinetobacter sp. & 8 & 0.57 & 7 & 0.49 & 4 & 0.30 & 19 & 0.46 \\
\hline Gram-negative organism & 18 & 1.29 & 10 & 0.70 & 11 & 0.81 & 39 & 0.93 \\
\hline Pseudomonas aeruginosa & 1 & 0.07 & 0 & 0.00 & 0 & 0.00 & 1 & 0.02 \\
\hline Pseudomonas sp. & 2 & 0.14 & 0 & 0.00 & 1 & 0.07 & 3 & 0.07 \\
\hline Serratia sp. & 0 & 0.00 & 1 & 0.07 & 0 & 0.00 & 1 & 0.02 \\
\hline \multicolumn{9}{|l|}{ Other } \\
\hline Prototheca sp. & 3 & 0.22 & 4 & 0.28 & 1 & 0.07 & 8 & 0.19 \\
\hline Yeast & 1 & 0.07 & 2 & 0.14 & 3 & 0.22 & 6 & 0.14 \\
\hline
\end{tabular}

${ }^{1}$ Treatment groups: BDCT $=$ blanket dry cow therapy; cult-SDCT $=$ culture-guided selective dry cow therapy; alg-SDCT $=$ algorithm-guided selective dry cow therapy.

${ }^{2}$ Quarters from cows that were excluded during the trial or retrospectively. Most exclusions were due to failure of subjects to calve 30 to $90 \mathrm{~d}$ after planned dry-off, antibiotic treatment less than $15 \mathrm{~d}$ before sampling, or failure to collect a sample within $13 \mathrm{~d}$ of calving.

${ }^{3}$ Streptococcus spp. and strep-like organisms. 
Table 5. Unconditional associations for possible predictors of quarter-level measures of udder health during the dry period

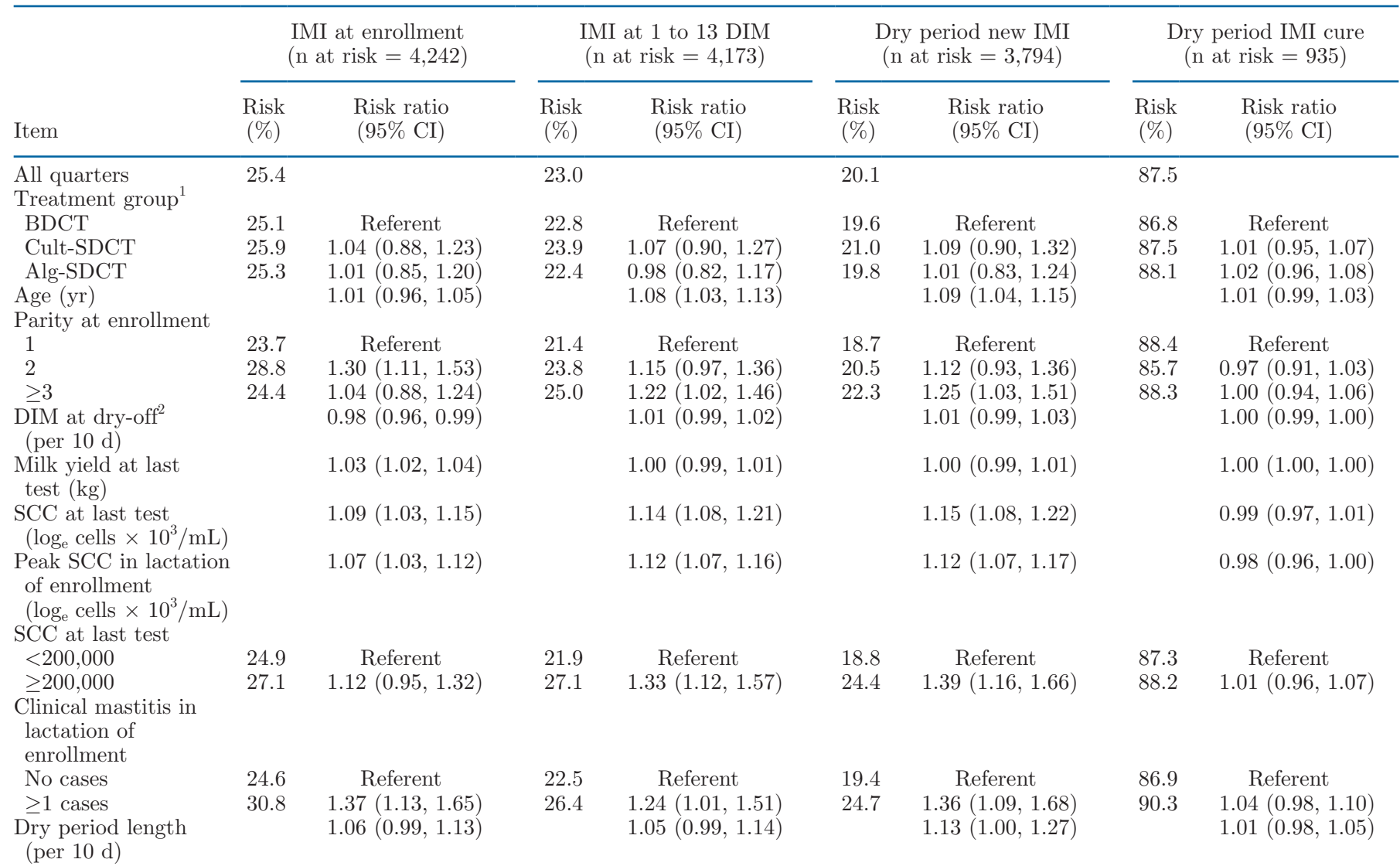

\footnotetext{
${ }^{1}$ Treatment groups: BDCT $=$ blanket dry cow therapy; cult-SDCT $=$ culture-guided selective dry cow therapy; alg-SDCT $=$ algorithm-guided selective dry cow therapy.

${ }^{2}$ Risk ratio estimates are per every $10 \mathrm{~d}$. For example, risk ratio for IMI at enrollment $=0.98$ means that risk of IMI at enrollment is $2 \%$ less for every additional 10 DIM at dry-off.
}

ed in Table 5. The crude dry period IMI cure risk for all quarters was $87.5 \%(818 / 935)$, which was similar in BDCT $(263 / 303,86.8 \%)$, cult-SDCT $(288 / 329,87.5 \%)$, and alg-SDCT $(267 / 303,88.1 \%)$ treatment groups. The final models evaluating the effects of treatment group on dry period IMI cure risk and new IMI are shown in Table 6. Adjusted cure risks and RD estimates were $89.7 \%$ in BDCT, $89.9 \%$ in cult-SDCT $(\mathrm{RD}=+0.2 \%$, 95\% CI: $-4.4,4.8 \%$ ), and $90.6 \%$ alg-SDCT (RD = $+0.9 \%, 95 \%$ CI: $-3.7,5.5 \%)$. The intraclass correlation coefficients for clustering of quarters within cows and cows within herds were 0.31 and 0.04 . The lower limits of the RD 2-sided 95\% confidence intervals for cult$\operatorname{SDCT}(-4.4 \%)$ and alg-SDCT $(-3.7 \%)$ quarters did not cross the a priori margin of non-inferiority $(-10 \%$ units), indicating that both SDCT approaches were non-inferior to, or "at least as good" as BDCT (Figure $3)$. The crude dry period new IMI risk for all quarters was $764 / 3,794(20.1 \%)$, which was similar in BDCT (246/1,255, 19.6\%), cult-SDCT (272/1,298, 21.0\%), and alg-SDCT $(246 / 1,241,19.8 \%)$ treatment groups.
Adjusted new IMI risks and RD estimates were 14.7\% for BDCT, $15.2 \%$ for cult-SDCT $(\mathrm{RD}=+0.5 \%, 95 \%$ CI: $-2.2,3.2 \%)$, and $14.7 \%$ alg-SDCT $(\mathrm{RD}=+0.0 \%$, $95 \%$ CI: $-2.6,2.7 \%$ ) quarters. The intraclass correlation coefficients for clustering of quarters within cows and cows within herds were 0.28 and 0.15 .

\section{DISCUSSION}

\section{SDCT Reduced Quarter-Level Antibiotic Use at Dry-Off by $55 \%$}

This study has demonstrated that quarter-level antibiotic use at dry-off can be substantially reduced using culture- or algorithm-guided SDCT. The observed reduction of $55 \%$ is consistent with other recent studies using similar approaches (Patel et al., 2017; Vasquez et al., 2018; Kabera et al., 2019; McParland et al., 2019). Although the reduction was the same in cult-SDCT and alg-SDCT quarters overall, they were rarely the same within a single herd. Furthermore, we found 
Table 6. Final generalized linear mixed models (logistic) estimating the effect of 2 selective dry cow therapy programs (compared with blanket dry cow therapy) ${ }^{1}$ on dry period IMI dynamics

\begin{tabular}{|c|c|c|c|c|c|}
\hline Item & $\begin{array}{l}\text { Adjusted } \\
\operatorname{risk}^{2}(\%)\end{array}$ & $\beta$ & $\mathrm{SE}$ & $\begin{array}{c}\text { Risk } \\
\text { difference }^{3}(\%)\end{array}$ & $\begin{array}{l}95 \% \text { CI of risk } \\
\text { difference }(\%)\end{array}$ \\
\hline \multicolumn{6}{|c|}{ Dry period IMI cure } \\
\hline BDCT & 89.7 & Referent & & & \\
\hline Cult-SDCT & 89.9 & 0.027 & 0.293 & +0.2 & $-4.4,4.8$ \\
\hline Alg-SDCT & 90.6 & 0.114 & 0.302 & +0.9 & $-3.7,5.5$ \\
\hline \multicolumn{6}{|c|}{ Dry period new IMI } \\
\hline $\mathrm{BDCT}$ & 14.7 & Referent & & & \\
\hline Cult-SDCT & 15.2 & 0.046 & 0.124 & +0.5 & $-2.2,3.2$ \\
\hline Alg-SDCT & 14.7 & 0.004 & 0.127 & +0.0 & $-2.6,2.7$ \\
\hline \multicolumn{6}{|c|}{ IMI postcalving } \\
\hline BDCT & 17.2 & Referent & & & \\
\hline Cult-SDCT & 17.5 & 0.028 & 0.119 & +0.3 & $-2.4,3.1$ \\
\hline Alg-SDCT & 16.7 & -0.038 & 0.122 & -0.5 & $-3.2,2.3$ \\
\hline
\end{tabular}

${ }^{1}$ Treatment groups: BDCT $=$ blanket dry cow therapy; cult-SDCT = culture-guided selective dry cow therapy; alg-SDCT $=$ algorithm-guided selective dry cow therapy.

${ }^{2}$ Risk estimates using predicted/estimated marginal means ( $\left.\sim \mathrm{LSM}\right)$.

${ }^{3}$ Risk difference estimates and $95 \%$ CI were derived from generalized linear mixed models using predicted or estimated marginal means in STATA ("marginal standardization"; STATA version 15; StataCorp, College Station, TX). Final model included random intercepts for cow and herd. All fixed-effect covariates were removed from the final model, as we found no evidence for confounding when using the $10 \%$ change in estimate approach. Intraclass correlation coefficients for dry period IMI cure for cow and herd were 0.31 and 0.04 , respectively. Intraclass correlation coefficients for dry period new IMI for cow and herd were 0.28 and 0.15 , respectively. Intraclass correlation coefficients for IMI at calving for cow and herd were 0.31 and 0.16 , respectively.

considerable among-herd variation in quarter-level antibiotic reductions, with wide ranges for both cultSDCT (32 to $68 \%$ ) and alg-SDCT (19 to $68 \%$ ) groups. This among-herd variation is likely to be influenced by several factors, including the prevalence of IMI and subclinical mastitis, incidence of clinical mastitis, and contamination risk when sampling milk for rapid culture. The cult-SDCT- and algorithm-guided SDCT had equivalent reductions in antibiotic use, which is inconsistent with a recent trial in Germany that found reductions of 23 and $55 \%$ for culture- and algorithmguided SDCT, respectively (tho Seeth et al., 2017).

\section{SDCT Had No Marked Negative Effects on Quarter- Level Measures of Udder Health}

This study found that cult-SDCT and alg-SDCT quarters had very similar risks to BDCT quarters for dry period IMI cure, dry period new IMI, and IMI at 1 to 13 DIM. The small and relatively precise (narrow 95\% CI) risk difference estimates indicate that, under the conditions of this trial, either SDCT approach is unlikely to cause marked effects on dry period IMI dynamics. This finding is consistent with the analysis for postcalving udder health (Rowe et al., 2020a), which found that neither SDCT program was likely to increase rates of clinical mastitis during 1 to 120 DIM (hazard ratio $(\mathrm{HR})_{\text {Cult-SDCT } / \mathrm{BDCT}}=0.82,95 \%$ CI: $0.58,1.15$; $\mathrm{HR}_{\mathrm{Alg} \text {-SDCT } / \mathrm{BDCT}}=0.83,95 \%$ CI: $\left.0.63,1.09\right)$ or test-day $\log _{\mathrm{e}} \mathrm{SCC}$ in the first 120 DIM (cult-SDCT $-\mathrm{BDCT}=$ $0.05,95 \%$ CI: $-0.09,0.18$; alg-SDCT - BDCT $=0.07$, 95\% CI: -0.07 , 0.21; Rowe et al., 2020a). The success of both SDCT approaches may be due to the relatively high negative predictive values for each screening test, which in this study were 0.87 and 0.80 , respectively (Rowe et al., 2020b). However, this high negative predictive value may be largely a function of low prevalence, as kappa values for agreement with laboratory culture were poor (0.09) for alg-SDCT and fair (0.28) for cult-SDCT. The methods, and discussion of these results, are presented in Rowe et al. (2020b).

\section{Culture-Guided SDCT}

The success of culture-guided SDCT in this trial is consistent with recent studies conducted in Canada using 3M Petrifilm (St. Paul, MN; Cameron et al., 2014; Kabera et al., 2019) and a recent pilot study using the Minnesota Easy 4Cast plate (Patel et al., 2017). In contrast, older field trials found that withholding antibiotic treatment from cows or quarters identified to be uninfected using laboratory culture resulted in increased dry period new IMI risk (Browning et al., 1990; Berry and Hillerton, 2002). One clear distinction (among others) between the successful and failed programs was that ITS were used in the successful programs, which is consistent with numerous studies that have consistently shown ITS to substantially reduce 
dry period new IMI risk (Rabiee and Lean, 2013). Our study is the first multi-herd trial of US herds to report outcomes for quarter-level culture-guided SDCT using the Minnesota Easy 4Cast plate. Before our study, culture-guided SDCT had only been evaluated using rapid culture of composite milk samples to make cowlevel treatment decisions (Cameron et al., 2014; tho Seeth et al., 2017). The main advantage of treating at the quarter level is that it might allow for greater reductions in antibiotic use at dry-off. For example, the reduction in quarter-level use in this study would have been only $23 \%$ if treatment had been allocated at the cow level, compared with the $55 \%$ reduction observed when allocating at the quarter level. This is because most cows $(59 \%)$ identified by laboratory culture to have an IMI were infected in a single quarter. However, incorporating all quarters into a single cow-level result may have some advantages. This is because quarters within the same cow are not truly independent of one another, as evidenced in our study by the high intraclass correlation coefficients for the 3 reported measures of dry period IMI dynamics shown in Table 6 (range 0.29 to 0.31). Consequently, the presence of an IMI in 1 quarter could be considered sufficient evidence to treat the remaining quarters of the same cow. Interpreting culture results within the same cow in parallel

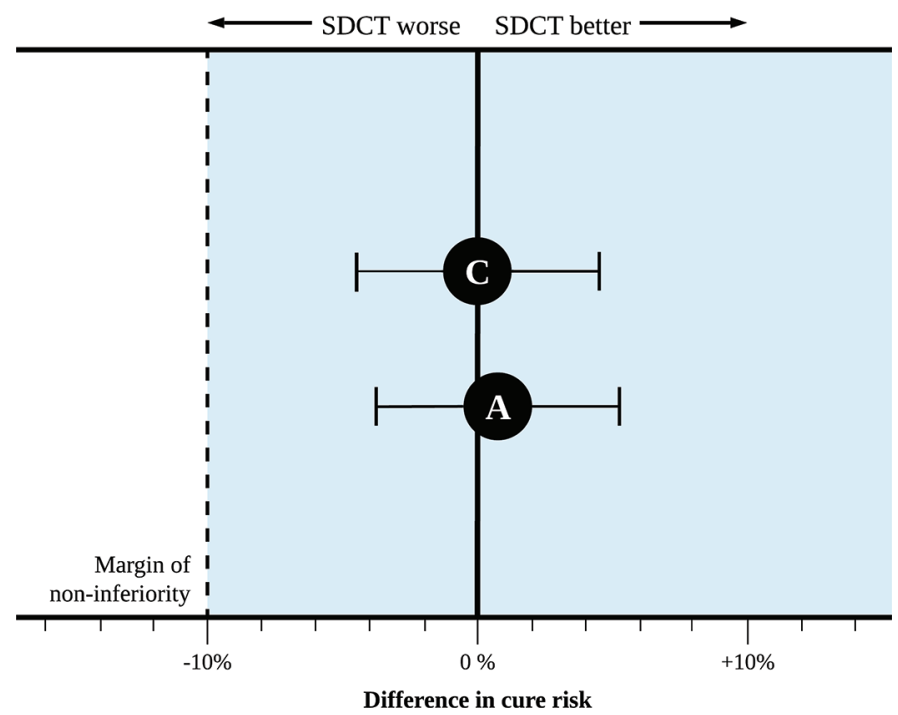

Figure 3. Non-inferiority analysis of dry period IMI cure risk for 2 selective dry cow therapy programs (SDCT), as compared with blanket dry cow therapy. $\mathrm{C}=$ culture-guided selective DCT group; $\mathrm{A}=$ algorithm-guided selective DCT group. Adjusted dry period cure risk in the BDCT group was $89.7 \%$, indicated by the solid vertical line. A margin or non-inferiority of $-10 \%$ was specified a priori, which is indicated by the dashed vertical line. For Cure and alg-SDCT quarters, the lower limit of the 2 -sided $95 \%$ CI for the risk difference (cf. BDCT) was greater than the margin of non-inferiority, indicating that both selective DCT approaches are non-inferior to blanket DCT. (i.e., cow level) could help to increase sensitivity, which has been shown to be low for certain pathogens. This is supported by the findings of a multi-herd trial of laboratory culture-guided SDCT in Australia, which found that quarter-level treatment (as was done in this study) resulted in a higher dry period new IMI risk (6.4\%) than cow-level SDCT $(3.9 \%)$ and BDCT $(2.6 \%$; Browning et al., 1994). In that study, the predominant cause of new IMI was Staphylococcus aureus, which typically spreads between quarters during lactation and not during the dry period. It is therefore possible that many of the "new infection" cases in that study were actually persistent infections that were not identified as infected at the dry-off sample due to failure of the screening system. Such a failure seems probable, given that Staphylococcus aureus is intermittently shed in milk of infected quarters, with one study estimating the sensitivity of a single milk sample to be $75 \%$ (Sears et al., 1990). The prevalence of Staphylococcus aureus IMI has declined significantly since the time of the Browning et al. (1994) study (Rowe et al., 2019), which may explain why quarter-level culture-guided SDCT performed as well as BDCT in our study and others (Patel et al., 2017; Kabera et al., 2019). In summary, our research indicates that quarter-level SDCT can be implemented without negative effects on IMI dynamics. However, this approach may not be appropriate in situations when the IMI at dry-off are caused by pathogens that are difficult to detect (i.e., lower sensitivity), behave contagiously, and have a significant influence on cow health if they escape treatment at dry-off (e.g., Staphylococcus aureus, Streptococcus agalactiae). This requires further investigation.

\section{Algorithm-Guided SDCT}

The effect of algorithm-guided SDCT on IMI dynamics is consistent with the results of some previous studies, which found negligible effects on IMI dynamics (Bradley et al., 2010; Vasquez et al., 2018). However, other SDCT studies using an algorithm-based approach have found clear deleterious effects (McDougall, 2010; Scherpenzeel et al., 2014). One clear distinction between the programs was the use of teat sealants in the successful programs. Another potential source of variability in responses to algorithm-guided SDCT is the algorithm itself. Many algorithms have been recommended by mastitis experts (Bradley et al., 2018; Gohary and McDougall, 2018; Vasquez et al., 2018), which use as few data points as possible (typically using only SCC and clinical mastitis data), to facilitate implementation under farm conditions. In the study by Scherpenzeel et al. (2014), the SCC component of 
their algorithm included only the most recent SCC measurement before dry-off. Our algorithm, and others (Bradley et al., 2010; Vasquez et al., 2018), interpreted multiple SCC measurements in parallel, which is expected to increase sensitivity. However, the unsuccessful algorithm protocol used by McDougall (2010) employed parallel interpretation of bi-monthly SCC measurements from the entire lactation and more conservative SCC (150,000 cells $/ \mathrm{mL})$ and clinical mastitis ( $\geq 1$ case) thresholds than in our study (200,000 cells/ $\mathrm{mL}$ and $\geq 2$ cases, respectively), suggesting that the lack of ITS used in that study was the likely reason for the program failure, and not accuracy of the algorithm. To our knowledge, no algorithm-guided SDCT trials have compared effects of different SCC cut points on measures of udder health. However, many algorithms with different SCC thresholds have been evaluated in their ability to predict IMI at dry-off (Pantoja et al., 2009; Gohary and McDougall, 2018; Lipkens et al., 2019). A recent multi-herd study in Belgium concluded that a single algorithm was unlikely to be highly accurate for all cows, and that other variables, such as herd-level estimates of subclinical mastitis prevalence, cow milk yield, and parity, should be incorporated into more sophisticated algorithms. The test characteristics of the algorithm used in this study, along with the Minnesota Easy 4Cast plate, are reported in Rowe et al. (2020b).

\section{Practical Considerations for SDCT Approaches Used in This Study}

This is the first study to directly compare antibiotic use and subsequent quarter health for SDCT programs using quarter-level culture and a cow-level algorithm. Given that both approaches yielded similar antibiotic reductions and health outcomes, it is likely that producers could use other factors to guide their decisions around SDCT implementation, such as feasibility and economics. The potential advantages of culture-guided SDCT include the fact that it does not require herds to conduct monthly DHIA testing or record clinical mastitis during lactation, which currently are practiced by approximately only $44 \%$ and $27 \%$ of herds in the United States, respectively (NAHMS, 2014b). Furthermore, the use of rapid culture systems may enable farmers to identify cows infected with pathogens of interest for specific interventions (e.g., culling Staphylococcus aureus cows), although this idea requires further study. One disadvantage of the culture-guided SDCT approach is that quarter-level detection and treatment adds complexity, increasing the potential for mistakes during the dry-off procedure.
One of the major advantages of algorithm-guided SDCT is that it efficiently utilizes data that is already available on many farms. Furthermore, allocation of treatments at the cow level is likely to be easier for farm staff to successfully implement than quarter-level treatments. Among the disadvantages of algorithm-guided SDCT are that it requires the herd to be participating in a DHIA testing program and to be accurately detecting and recording clinical mastitis events into electronic herd records. Furthermore, several studies have shown the algorithms are not sensitive predictors of IMI caused by "minor" pathogens such as NAS and Corynebacterium spp., because such IMI often fail to increase SCC above commonly used SCC thresholds (e.g., 200,000 cells/mL; Gohary and McDougall, 2018). However, this potential limitation may actually be an advantage, as it is unclear whether quarters infected with minor pathogens benefit from antibiotic treatment. Previous studies have found that NAS IMI at dry-off have a high spontaneous dry period cure risk (Vasquez et al., 2018) and often have minimal effects on clinical mastitis risk (Green et al., 2002) or milk production in the subsequent lactation (Vanderhaeghen et al., 2014). Given that NAS are the main cause of IMI at dry-off, we believe that more research is needed to investigate the importance of treatment of NAS-infected quarters. The economic impact of each approach is likely to be a potent driver of farmer decisions around SDCT. Currently, economic modeling of DCT approaches under US conditions has not yet been conducted; therefore, we plan to address this using stochastic modeling methods in a separate study. Economic modeling of BDCT and algorithm-guided SDCT in the Netherlands has found that algorithm-guided SDCT resulted in higher net financial gains than BDCT, despite having some negative effects on cow health (Scherpenzeel et al., 2016, 2018).

Regardless of the program selected, implementation of a successful SDCT program will require some consideration of appropriate selection of candidate farms, and careful attention to correctly manage and implement the program. Although no formal research exists on the question of farm selection, mastitis experts have suggested that herds free from Streptococcus agalactiae and with bulk tank SCC below 250,000 cells/mL may be most likely to benefit from SDCT (Bradley et al., 2018). In addition, we believe it is important that candidate farms have excellent record management, train farm staff to successfully use the culture or algorithm technology, and ensure strict adherence to clean intramammary infusion techniques, particularly when infusing a quarter with ITS alone. We believe that SDCT programs represent an opportunity for local veterinary 
practices to offer the necessary services for candidate farms that are not willing or capable of managing an SDCT program with their own staff. For example, for those farms not interested in or able to set up a successful on-farm culture program, it is possible that in-house rapid culture services could be provided by the local veterinary clinic. Furthermore, trained veterinary technicians could offer related services, including aseptic collection of milk samples for culture before dry-off, accurate interpretation of culture (or algorithm) results, and clean, correctly applied infusion of the assigned treatments on the day of dry-off.

\section{Prevalence of IMI at Dry-Off and Antibiotic Choice}

The quarter-level prevalence of IMI at enrollment (2 d before dry-off) was $25 \%$, which is similar to a recent US survey of over 10,000 quarters of late-lactation cows from 80 herds in 10 states, which found a prevalence of $21 \%$ (Rowe et al., 2019). In the current study, most infections were caused by gram-positive bacteria $(1,024$ of 1,078 infected quarters, 95\%), which were mostly NAS (629 of 1,078 infected quarters, 58\%). The most common pathogens were Staphylococcus chromogenes (8\% of quarters at risk) and Staphylococcus spp. (i.e., underdetermined species, $4 \%)$. Only 63 of $4,242(1.5 \%)$ quarters at risk were infected with gram-negative bacteria, which accounted for only $5.8 \%$ of all infected quarters. This is consistent with the Rowe et al. (2019) study, which found a gram-negative prevalence of $0.8 \%$ (3\% of infected quarters). This low prevalence of gramnegative IMI at dry-off may explain why some recent clinical trials have found no difference in dry period IMI cure and new IMI risk in quarters treated with narrow or broad-spectrum antimicrobials (Arruda et al., 2013; Johnson et al., 2016). Despite the questionable advantages of using broad-spectrum antibiotics at dry-off, we chose to use a broad-spectrum antibiotic (500 mg of ceftiofur hydrochloride) as part of our DCT protocols, as we wanted to validate our SDCT approaches against a BDCT protocol that is likely to be perceived by veterinarians and producers as being "comprehensive." Other successful SDCT protocols have used third- (Cameron et al., 2014) and first-generation cephalosporin antibiotics (Bradley et al., 2010; Vasquez et al., 2018), which are respectively broad and narrow in their spectra of activity. In light of these studies, and those showing similar health outcomes for narrow- and broad-spectrum antibiotics used in BDCT protocols, we think sufficient evidence exists to suggest that SDCT could be successfully implemented using narrow-spectrum antibiotics. However, this requires further investigation.

\section{IMI Risk at 1 to 13 DIM and Infection Dynamics over the Dry Period}

Non-aureus Staphylococcus spp. were the predominant cause of IMI at 1 to 13 DIM (544 of 961 infected quarters, $57 \%$ ), which is very similar to the proportion $(58 \%)$ at enrollment. The predominant NAS was Staphylococcus chromogenes (4.6\% of quarters at risk) and Staphylococcus spp. (4.7\%), which were also the predominant causes of IMI at enrollment. The prevalence of Staphylococcus sciuri at 1 to 13 DIM (3.1\%) was much higher than the prevalence at dry-off $(0.4 \%)$, which indicates that the majority of these infections were acquired from the environment during the dry period. This hypothesis is supported by a study by Piessens et al. (2011), which showed that the reservoirs for Staphylococcus sciuri IMI were commonly found in the environment, less often in cow-associated reservoirs. The prevalence of gram-negative IMI at 1 to 13 DIM was only $1.9 \%$, which is similar to the prevalence at dry-off $(1.5 \%)$. This finding is not consistent with other studies that have shown higher prevalences at calving, due to new gram-negative IMI acquired during the dry period. For example, a recent observational study of 1,816 quarters from 12 European dairy herds found that the prevalence of gram-negative IMI at dry-off and postcalving were 2.8 and $4.8 \%$, respectively (Bradley et al., 2015). In that study, ITS were not used, which may explain why gram-negative IMI increased over the dry period. The crude dry period IMI cure risk in our study was $87.5 \%$. This number is similar to recent studies that have found IMI cure risks of 90\% (Ospina et al., 2016), 89\% (Arruda et al., 2013), 85\% (Johnson et al., 2016), and 80\% (Bradley et al., 2010). The crude dry period new IMI risk in our study was $20.1 \%$, which is similar to recent studies that found new IMI risks of 13\% (Arruda et al., 2013), 19\% (Johnson et al., 2016), and 30\% (Bradley et al., 2010).

\section{Study Strengths and Limitations}

Study Design. One considerable strength of this study is the large number of quarters enrolled $(\sim 1,700$ per treatment group), which provided precise RD estimates (i.e., relatively narrow 95\% CI). Furthermore, this is the first SDCT study to use a non-inferiority design, which, in our opinion, is more appropriate than superiority designs for showing "sameness" between groups. However, we conducted a non-inferiority hypothesis test only for dry period IMI cure risk (Figure 3 ), because this was the primary outcome of interest. For dry period new IMI and IMI at 1 to 13 DIM risk, no non-inferiority hypothesis tests were conducted, and 
instead, $95 \%$ confidence intervals were reported, which also clearly demonstrated that the effect of SDCT on these measures of udder health is likely to be weak or absent.

Internal Validity. Confounding and selection bias are unlikely sources of bias in our study. Our randomization method appeared to be effective, given the balance of herds and demographic details between treatment groups at baseline (Table 2). In addition, no covariates were found to change effect estimates by $>10 \%$ when they were removed from models, indicating little or no measured confounding. We found no evidence for differential loss to follow-up, which included losses during the dry period due to death or culling and for antibiotic treatments in early lactation, indicating that the effect estimates reported in this study are not likely to be biased by drop-out. Furthermore, losses due to contaminated or non-collected milk samples were similar among treatment groups. The largest effect of these losses from enrollment to calving $(17 \%)$ was a reduction in sample size, which would likely have reduced the precision of effect estimates (i.e., widening of 95\% CI).

It is important to consider potential sources of information bias. The outcome variables in this study were based on IMI measurements taken at enrollment and at 1 to 13 DIM. Intramammary infection dynamics are commonly used as an udder health measure in DCT research, as they are associated with more tangible measures of udder health, such as clinical mastitis (Green et al., 2002), but can be measured in an objective, consistent way across multiple herds and sites. To achieve this in our study, laboratory staff at each site were instructed to follow a standardized protocol and to use the same culture mediums and equipment (i.e., MALDI-TOF). However, the use of milk culture to identify IMI has some limitations. First, milk culture is not $100 \%$ sensitive nor $100 \%$ specific. One study found that the sensitivity and specificity of a single milk culture were 70 and 90\%, respectively (Dohoo et al., 2011a), which would lead to misclassification of infected and uninfected quarters. However, we believe this potential misclassification would have been the same for quarters of all 3 treatment groups (i.e., non-differential), which, in most cases, causes a bias that reduces the estimated effect size (i.e., "observed" RD are closer to 0 than the "true" RD). This potential source of information bias is important to consider in non-inferiority and equivalence studies, as it can cause investigators to incorrectly conclude that treatment groups are the same. In our study, we proactively took steps to address potential information bias and thus improve our chances of detecting a difference in IMI dynamics between groups. First, we used cfu thresholds for NAS and Bacillus spp. isolates to increase specificity, which has a more profound bias- ing effect than does sensitivity (Haine et al., 2018). We decided this for NAS because they are the most common cause of IMI at dry-off (Rowe et al., 2019), and diagnostic specificity using milk culture from a single sample is worse than for other pathogens (Dohoo et al., 2011b). We used a similar approach for Bacillus spp. Some recent SDCT studies (Cameron et al., 2014), but not all (Scherpenzeel et al., 2014), have used cfu thresholds. In addition to cfu thresholds, we used MALDITOF mass spectrometry in the diagnosis of pathogens, which has been shown to be superior to traditional biochemical testing methods, especially when an expanded database is used (Barreiro et al., 2010; Wanecka et al., 2019), which had been done before the study as part of each laboratory's quality control program. Having highly accurate diagnoses is particularly important in determining dry period IMI dynamics. For example, a quarter infected with Staphylococcus chromogenes at dry-off and then Staphylococcus haemolyticus at calving can be correctly identified using MALDI-TOF as cure $=1$ (Staphylococcus chromogenes) and new IMI $=1$ (Staphylococcus haemolyticus). In contrast, traditional laboratory methods would often classify both of these IMI as CNS, and the quarter would be incorrectly classified as cure $=0$ and new IMI $=0$. However, we did find that a substantial proportion of NAS isolates in enrollment (27\%) and postcalving (36\%) milk samples could not be identified at the species level.

External Validity. We believe that our research is relevant to a large proportion of American dairy farmers, because cows were enrolled from 7 herds located in the southwest, midwest, and northeast dairy farming regions of the United States. However, the herd inclusion criteria used in this study need to be considered when relating our results to individual dairy herds. These criteria included an existing relationship with the University of Minnesota, Cornell University, Iowa State University, DairyExperts Inc., or Dairy Health and Management Services, and requirements to be drying off at least 15 cows per week, have a bulk milk SCC $<250,000$ cells $/ \mathrm{mL}$, be on a monthly DHIA testing schedule, and have high-quality clinical mastitis and culling records. Another important consideration is that the dry-off protocols in this trial were conducted by study technicians and not farm staff, including collection of milk samples, reading of Minnesota Easy 4Cast plates, and administration of intramammary treatments. We think it is possible that some herds with poor mastitis control (which could be identified as SCC $>250,000$ cells $/ \mathrm{mL}$, or poor control of pathogens such as Staphylococcus aureus and Streptococcus agalactiae), or herds unable to carefully implement a SDCT program, may be at a higher risk of the SDCT-related adverse health events that were observed in other trials 
(Berry and Hillerton, 2002; Scherpenzeel et al., 2014). Furthermore, it should be noted that the incidence of clinical mastitis in the lactation before enrollment for the cows in this study was $13.8 \%$, which may less than on some US dairy herds. The most recent NAHMS survey of US dairy farms (NAHMS, 2014a) estimates that $24.8 \%$ of cows experience at least 1 case of clinical mastitis per lactation, and that risk of culling or death for cows with clinical mastitis is $27.2 \%$. Therefore, the proportion of cows that reach dry-off with a history of clinical mastitis may be approximately $18.1 \%$ (i.e., $24.8 \% \times 1-27.2 \%$ ). Consequently, it is likely that the herds selected into this study have better mastitis control than the average US farm.

To our knowledge, no randomized controlled trials have evaluated farmer-implemented SDCT protocols. Furthermore, no observational studies have directly evaluated herd-level factors that might modify the effect of SDCT on dry period IMI dynamics. Another important limitation to the generalizability of this study is that cows were followed for a relatively short period, which may reduce generalizability to other seasonal conditions. One of the perceived risks of SDCT is that historically important pathogens such as Staphylococcus aureus and Streptococcus agalactiae could gradually increase in prevalence over multiple lactations, which would not be identified in the current SDCT trial. Consequently, we recommend that herds implementing SDCT conduct routine surveillance for these pathogens, using individual cow and bulk milk testing, in addition to monitoring DHIA SCC data for changes in infection dynamics.

\section{Future Research}

Further work in the multi-site project will investigate the economic and microbiome effects of SDCT. Further research on SDCT as implemented by farm staff (rather than research technicians) would further evaluate the suitability of SDCT on US dairy farms. In addition, more work is needed to evaluate herd factors that influence the suitability of SDCT. Finally, more research is necessary to refine the existing SDCT protocols evaluated in this study, to further reduce antibiotic use. For example, research is needed to evaluate protocols that use narrow-spectrum antibiotics or that omit certain IMI, such as NAS, from treatment.

\section{CONCLUSIONS}

In a multi-site, randomized, natural exposure, noninferiority trial, culture- and algorithm-guided SDCT each reduced antibiotic use by $55 \%$ without having a marked effect on risk of IMI cure and new IMI during the dry period and IMI prevalence at 1 to 13 DIM. The findings from this study and others indicate that SDCT can be successfully implemented on appropriate commercial dairy herds in the United States.

\section{ACKNOWLEDGMENTS}

We are very grateful for the participation and tremendous cooperation by owners and staff at the 7 participating dairies. We also thank the technicians that assisted at each study site: California (Maria Amaral, Gema Camacho, Pablo Duque, Pallavi Nahata, Kruthika Patel, Maria Jose Perez, Cinthya Tovar, and Juanita Zaragoza; DairyExperts, Tulare, CA), Iowa (Jordan Stratman, Courtney Behrens, Emily Schwake, and Austin Ashbacher; Iowa State University, Ames), Minnesota (Kelli Bowman, Joshua Brown, Pedro Paulo Cecillio Ferro, Chandra Dahike, Kaylan Risacher, and Victor Moro Taveira; University of Minnesota, St. Paul), and New York (Lauren Pitman and Michaela Thomas; Cornell University, Ithaca, NY). We also thank Richard Maclehose and Darin Erickson (both at University of Minnesota) for their input on statistical methods. S. M. Rowe was involved in local and multi-site coordination, fieldwork, laboratory work, data management, statistical analysis, and manuscript preparation. S. M. Godden was involved in study conceptualization, herd recruitment in Minnesota and Wisconsin, and supervision of fieldwork and manuscript editing. P. Gorden and A. Lago were involved in study conceptualization, local site coordination, fieldwork, and manuscript editing. D. V. Nydam was involved in study conceptualization, New York herd recruitment, local site coordination, and manuscript editing. A. K. Vasquez was involved in fieldwork, local site coordination, and manuscript editing. E. Royster was involved in study conceptualization and manuscript editing. J. Timmerman was involved in laboratory work and manuscript editing. M. J. Thomas was involved in local site coordination, fieldwork, and manuscript editing. This study was funded by the United States Department of Agriculture National Institute for Food and Agriculture (NIFA, Washington, DC; Award \# 2018-67015-28298) and was supported by an in-kind donation of product (Spectramast DC, Orbeseal) from Zoetis (Parsippany, NJ). The Minnesota Easy 4Cast plate is manufactured by the University of Minnesota (St. Paul, MN). However, the study investigators have no financial interest in the sale of this plate. The authors have not stated any other conflicts of interest.

\section{REFERENCES}

Arruda, A. G., S. Godden, P. Rapnicki, P. Gorden, L. Timms, S. S. Aly, T. W. Lehenbauer, and J. Champagne. 2013. Randomized 
noninferiority clinical trial evaluating 3 commercial dry cow mastitis preparations: I. Quarter-level outcomes. J. Dairy Sci. 96:44194435. https://doi.org/10.3168/jds.2012-6461.

Barreiro, J. R., C. R. Ferreira, G. B. Sanvido, M. Kostrzewa, T. Maier, B. Wegemann, V. Böttcher, M. N. Eberlin, and M. V. Dos Santos. 2010. Identification of subclinical cow mastitis pathogens in milk by matrix-assisted laser desorption/ionization time-of-flight mass spectrometry. J. Dairy Sci. 93:5661-5667. https://doi.org/10 $.3168 /$ jds.2010-3614.

Berry, E. A., and J. E. Hillerton. 2002. The effect of selective dry cow treatment on new intramammary infections. J. Dairy Sci. 85:112121. https://doi.org/10.3168/jds.S0022-0302(02)74059-9.

Bradley, A. J., J. E. Breen, B. Payne, P. Williams, and M. J. Green. 2010. The use of a cephalonium containing dry cow therapy and an internal teat sealant, both alone and in combination. J. Dairy Sci. 93:1566-1577. https://doi.org/10.3168/jds.2009-2725.

Bradley, A., S. De Vliegher, M. Farre, L. M. Jimenez, T. Peters, E. S. de Leemput, and T. van Werven. 2018. Pan-European agreement on dry cow therapy. Vet. Rec. 182:637. https://doi.org/10.1136/ vr.k2382.

Bradley, A. J., S. De Vliegher, M. J. Green, P. Larrosa, B. Payne, E. S. van de Leemput, O. Samson, D. Valckenier, T. Van Werven, H. W. Waldeck, V. White, and L. Goby. 2015. An investigation of the dynamics of intramammary infections acquired during the dry period on European dairy farms. J. Dairy Sci. 98:6029-6047. https: //doi.org/10.3168/jds.2014-8749.

Browning, J. W., G. A. Mein, M. Barton, T. J. Nicholls, and P. Brightling. 1990. Effects of antibiotic therapy at drying off on mastitis in the dry period and early lactation. Aust. Vet. J. 67:440-442. https: //doi.org/10.1111/j.1751-0813.1990.tb03055.x.

Browning, J. W., G. A. Mein, P. Brightling, T. J. Nicholls, and M. Barton. 1994. Strategies for mastitis control: Dry cow therapy and culling. Aust. Vet. J. 71:179-181. https://doi.org/10.1111/j.1751 -0813.1994.tb03383.x.

Cameron, M., S. L. McKenna, K. A. MacDonald, I. R. Dohoo, J. P. Roy, and G. P. Keefe. 2014. Evaluation of selective dry cow treatment following on-farm culture: Risk of postcalving intramammary infection and clinical mastitis in the subsequent lactation. J. Dairy Sci. 97:270-284. https://doi.org/10.3168/jds.2013-7060.

Dohoo, I., S. Andersen, R. Dingwell, K. Hand, D. Kelton, K. Leslie, Y. Schukken, and S. Godden. 2011a. Diagnosing intramammary infections: Comparison of multiple versus single quarter milk samples for the identification of intramammary infections in lactating dairy cows. J. Dairy Sci. 94:5515-5522. https://doi.org/10.3168/jds.2011 -4486 .

Dohoo, I. R., C. R. Nielsen, and U. Emanuelson. 2016. Multiple imputation in veterinary epidemiological studies: A case study and simulation. Prev. Vet. Med. 129:35-47. https://doi.org/10.1016/j .prevetmed.2016.04.003.

Dohoo, I. R., J. Smith, S. Andersen, D. F. Kelton, and S. Godden. 2011b. Diagnosing intramammary infections: Evaluation of definitions based on a single milk sample. J. Dairy Sci. 94:250-261. https://doi.org/10.3168/jds.2010-3559.

Edmonson, A., I. Lean, L. Weaver, T. Farver, and G. Webster. 1989. A body condition scoring chart for Holstein dairy cows. J. Dairy Sci. 72:68-78. https://doi.org/10.3168/jds.S0022-0302(89)79081-0.

Gohary, K., and S. McDougall. 2018. Predicting intramammary infection status at drying off using indirect testing of milk samples. N. Z. Vet. J. 66:312-318. https://doi.org/10.1080/00480169.2018 .1509741

Green, M. J., L. E. Green, G. F. Medley, Y. H. Schukken, and A. J. Bradley. 2002. Influence of dry period bacterial intramammary infection on clinical mastitis in dairy cows. J. Dairy Sci. 85:2589 2599. https://doi.org/10.3168/jds.S0022-0302(02)74343-9.

Greenland, S., and N. Pearce. 2015. Statistical foundations for modelbased adjustments. Annu. Rev. Public Health 36:89-108. https:// doi.org/10.1146/annurev-publhealth-031914-122559.

Haine, D., I. Dohoo, and S. Dufour. 2018. Selection and misclassification biases in longitudinal studies. Front. Vet. Sci. 5:99. https:// doi.org/10.3389/fvets.2018.00099.
Halasa, T., M. Nielen, A. C. Whist, and O. Osteras. 2009a. Metaanalysis of dry cow management for dairy cattle. Part 2. Cure of existing intramammary infections. J. Dairy Sci. 92:3150-3157. https://doi.org/10.3168/jds.2008-1741.

Halasa, T., O. Osteras, H. Hogeveen, T. van Werven, and M. Nielen. 2009b. Meta-analysis of dry cow management for dairy cattle. Part 1. Protection against new intramammary infections. J. Dairy Sci. 92:3134-3149. https://doi.org/10.3168/jds.2008-1740.

Johnson, A. P., S. M. Godden, E. Royster, S. Zuidhof, B. Miller, and J. Sorg. 2016. Randomized noninferiority study evaluating the efficacy of 2 commercial dry cow mastitis formulations. J. Dairy Sci. 99:593-607. https://doi.org/10.3168/jds.2015-10190.

Kabera, F., S. Dufour, G. Keefe, and J. P. Roy. 2019. Quarter-based selective dry cow therapy using on-farm diagnostics: Results of a randomized controlled trial. Pages 149-150 in Proc. 58th Annual Meeting of the National Mastitis Council, Savannah, GA. National Mastitis Council, New Prague, MN.

Lipkens, Z., S. Piepers, A. De Visscher, and S. De Vliegher. 2019. Evaluation of test-day milk somatic cell count information to predict intramammary infection with major pathogens in dairy cattle at drying off. J. Dairy Sci. 102:4309-4321. https://doi.org/ 10.3168/jds.2018-15642.

McDougall, S. 2010. A randomised, non-inferiority trial of a new cephalonium dry-cow therapy. N. Z. Vet. J. 58:45-58. https://doi.org/ 10.1080/00480169.2010.65060.

McParland, S., P. Dillon, J. Flynn, N. Ryan, S. Arkins, and A. Kennedy. 2019. Effect of using internal teat sealant with or without antibiotic therapy at dry-off on subsequent somatic cell count and milk production. J. Dairy Sci. 102:4464-4475. https://doi.org/10 .3168/jds.2018-15195.

Muller, C. J., and R. F. MacLehose. 2014. Estimating predicted probabilities from logistic regression: Different methods correspond to different target populations. Int. J. Epidemiol. 43:962-970. https:/ /doi.org/10.1093/ije/dyu029.

NAHMS (National Animal Health Monitoring System). 2014a. Milk Quality, Milking Procedures, and Mastitis in the United States. USDA-APHIS-VS-CEAH-National Animal Health Monitoring System, Fort Collins, CO.

NAHMS (National Animal Health Monitoring System). 2014b. Dairy Cattle Management Practices in the United States. USDA-APHISVS-CEAH-National Animal Health Monitoring System, Fort Collins, $\mathrm{CO}$.

National Mastitis Council (NMC). 2017. Laboratory Handbook on Bovine Mastitis. NMC, Madison, WI.

O'Connor, A. M., J. M. Sargeant, I. A. Gardner, J. S. Dickson, M. E. Torrence, and I. D. consensus meeting participants. 2010. The REFLECT statement: Methods and processes of creating reporting guidelines for randomized controlled trials for livestock and food safety. J. Vet. Intern. Med. 24:57-64. https://doi.org/10.1111/j .1939-1676.2009.0441.x.

Ospina, P. A., N. Rota, C. Locatelli, L. Colombo, C. Pollera, G. Giacinti, V. Bronzo, A. Casula, A. Arpinelli, V. Brossette, M. Facchi, A. Patelli, A. Ruggeri, A. Barberio, G. Potenza, D. V. Nydam, and P. Moroni. 2016. Randomized noninferiority field trial comparing 2 first-generation cephalosporin products at dry off in quarters receiving an internal teat sealant in dairy cows. J. Dairy Sci. 99:6519-6531. https://doi.org/10.3168/jds.2015-10807.

Pantoja, J. C., C. Hulland, and P. L. Ruegg. 2009. Dynamics of somatic cell counts and intramammary infections across the dry period. Prev. Vet. Med. 90:43-54. https://doi.org/10.1016/j.prevetmed 2009.03.012.

Patel, K., S. Godden, E. Royster, J. Timmerman, B. Crooker, and N. McDonald. 2017. Pilot study: Impact of using a culture-guided selective dry cow therapy program targeting quarter-level treatment on udder health and antibiotic use. Bov. Pract. 51:48-57.

Piaggio, G., D. R. Elbourne, D. G. Altman, S. J. Pocock, and S. J. Evans., and CONSORT Group. 2006. Reporting of noninferiority and equivalence randomized trials: An extension of the CONSORT statement. JAMA 295:1152-1160. https://doi.org/10.1001/jama .295.10.1152. 
Piessens, V., E. Van Coillie, B. Verbist, K. Supré, G. Braem, A. Van Nuffel, L. De Vuyst, M. Heyndrickx, and S. De Vliegher. 2011. Distribution of coagulase-negative Staphylococcus species from milk and environment of dairy cows differs between herds. J. Dairy Sci 94:2933-2944. https://doi.org/10.3168/jds.2010-3956.

Pol, M., and P. Ruegg. 2007. Treatment practices and quantification of antimicrobial drug usage in conventional and organic dairy farms in Wisconsin. J. Dairy Sci. 90:249-261. https://doi.org/10.3168/ jds.S0022-0302(07)72626-7.

R Core Team. 2018. R: A Language and Environment for Statistical Computing. R Foundation for Statistical Computing, Vienna, Austria.

Rabiee, A. R., and I. J. Lean. 2013. The effect of internal teat sealant products (Teatseal and Orbeseal) on intramammary infection, clinical mastitis, and somatic cell counts in lactating dairy cows: A meta-analysis. J. Dairy Sci. 96:6915-6931. https://doi.org/10 $.3168 /$ jds.2013-6544.

Rowe, S. M., S. M. Godden, E. Royster, J. Timmerman, B. A. Crooker, and M. Boyle. 2019. Cross-sectional study of the relationship among bedding materials, bedding bacteria counts, and intramammary infection in late-lactation dairy cows. J. Dairy Sci. 102:11384-11400. https://doi.org/10.3168/jds.2019-17074.

Rowe, S. M., S. M. Godden, D. V. Nydam, P. J. Gorden, A. Lago, A. K. Vasquez, E. Royster, J. Timmerman, and M. J. Thomas. 2020a. Randomized controlled trial investigating the effect of two selective dry cow therapy protocols on udder health and performance in the subsequent lactation. J. Dairy Sci. 103:6493-6503. https:// doi.org/10.3168/jds.2019-17961.

Rowe, S. M., S. M. Godden, D. V. Nydam, P. J. Gorden, A. Lago, A. K. Vasquez, E. Royster, J. Timmerman, and M. J. Thomas. 2020b. Evaluation of rapid culture, a predictive algorithm, esterase somatic cell count and lactate dehydrogenase to detect intramammary infection in quarters of dairy cows at dry-off. Prev. Vet. Med. 179:104982. https://doi.org/10.1016/j.prevetmed.2020.104982.

Scherpenzeel, C. G. M., H. Hogeveen, L. Maas, and T. J. G. M. Lam. 2018. Economic optimization of selective dry cow treatment. J. Dairy Sci. 101:1530-1539. https://doi.org/10.3168/jds.2017-13076.

Scherpenzeel, C. G. M., I. E. M. den Uijl, G. van Schaik, R. G. M. Olde Riekerink, J. M. Keurentjes, and T. J. G. M. Lam. 2014 Evaluation of the use of dry cow antibiotics in low somatic cell count cows. J. Dairy Sci. 97:3606-3614. https://doi.org/10.3168/ jds.2013-7655.

Scherpenzeel, C. G. M., I. E. M. den Uijl, G. van Schaik, R. G. M. Olde Riekerink, H. Hogeveen, and T. J. G. M. Lam. 2016. Effect of different scenarios for selective dry-cow therapy on udder health, antimicrobial usage, and economics. J. Dairy Sci. 99:3753-3764. https://doi.org/10.3168/jds.2015-9963.

Sears, P. M., B. S. Smith, P. B. English, P. S. Herer, and R. N. Gonzalez. 1990. Shedding pattern of Staphylococcus aureus from bovine intramammary infections. J. Dairy Sci. 73:2785-2789. https://doi .org/10.3168/jds.S0022-0302(90)78964-3.

Sprecher, D. J., D. E. Hostetler, and J. B. Kaneene. 1997. A lameness scoring system that uses posture and gait to predict dairy cattle reproductive performance. Theriogenology 47:1179-1187. https:// doi.org/10.1016/S0093-691X(97)00098-8.

tho Seeth, M., N. Wente, J.-H. Paduch, D. Klocke, E. Mansion-de Vries, M. Hoedemaker, and V. Krömker. 2017. Different selective dry cow therapy concepts compared to blanket antibiotic dry cow treatment. Tierärztliche Praxis Ausgabe G: Großtiere/Nutztiere 45:343-349.

Vanderhaeghen, W., S. Piepers, F. Leroy, E. Van Coillie, F. Haesebrouck, and S. De Vliegher. 2014. Invited review: Effect, persistence, and virulence of coagulase-negative Staphylococcus species associated with ruminant udder health. J. Dairy Sci. 97:5275-5293. https://doi.org/10.3168/jds.2013-7775.

Vanhoudt, A., K. van Hees-Huijps, A. van Knegsel, O. Sampimon, J. Vernooij, M. Nielen, and T. van Werven. 2018. Effects of reduced intramammary antimicrobial use during the dry period on udder health in Dutch dairy herds. J. Dairy Sci. 101:3248-3260. https:// doi.org/10.3168/jds.2017-13555.

Vasquez, A. K., D. V. Nydam, C. Foditsch, M. Wieland, R. Lynch, S. Eicker, and P. D. Virkler. 2018. Use of a culture-independent on-farm algorithm to guide the use of selective dry-cow antibiotic therapy. J. Dairy Sci. 101:5345-5361. https://doi.org/10.3168/jds .2017-13807.

Wanecka, A., J. Król, J. Twardoń, J. Mrowiec, A. Korzeniowska-Kowal, and A. Wzorek. 2019. Efficacy of MALDI-TOF mass spectrometry as well as genotypic and phenotypic methods in identification of staphylococci other than Staphylococcus aureus isolated from intramammary infections in dairy cows in Poland. J. Vet. Diagn. Invest. 31:523-530. https://doi.org/10.1177/1040638719845423.

Wasserstein, R. L., and N. A. Lazar. 2016. The ASA's statement on p-values: Context, process, and purpose. Am. Stat. 70:129-133. https://doi.org/10.1080/00031305.2016.1154108.

\section{ORCIDS}

S. M. Rowe @ https://orcid.org/0000-0001-8336-6523

S. M. Godden $\odot$ https://orcid.org/0000-0002-4438-0039

D. V. Nydam (1) https://orcid.org/0000-0001-7717-4859

P. J. Gorden @ https://orcid.org/0000-0002-6096-0965

A. Lago (i https://orcid.org/0000-0003-0380-0292

A. K. Vasquez (1) https://orcid.org/0000-0001-7639-0154

E. Royster (1) https://orcid.org/0000-0002-8298-5581

M. J. Thomas () https://orcid.org/0000-0002-6837-7352 